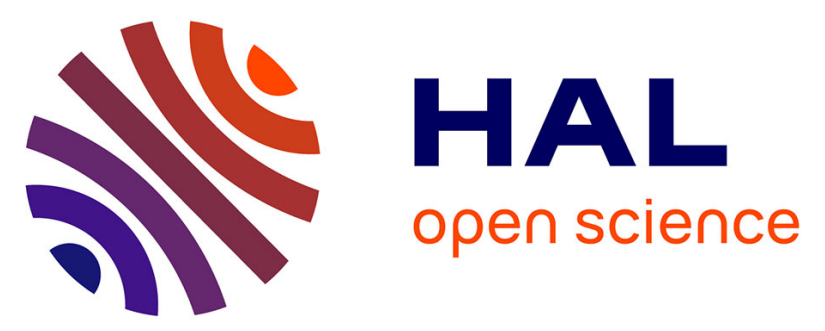

\title{
Sensorless Adaptive Output Feedback Control of Wind Energy Systems with PMS Generators
}

Abdelmounime El Magri, Fouad Giri, Gildas Besancon, Abderrahim Elfadili, Luc Dugard, Fatima Zara Chaoui

\section{- To cite this version:}

Abdelmounime El Magri, Fouad Giri, Gildas Besancon, Abderrahim Elfadili, Luc Dugard, et al.. Sensorless Adaptive Output Feedback Control of Wind Energy Systems with PMS Generators. Control Engineering Practice, 2013, 21 (4), pp.530-543. 10.1016/j.conengprac.2012.11.005 . hal-00764404

\section{HAL Id: hal-00764404 https://hal.science/hal-00764404}

Submitted on 13 Dec 2012

HAL is a multi-disciplinary open access archive for the deposit and dissemination of scientific research documents, whether they are published or not. The documents may come from teaching and research institutions in France or abroad, or from public or private research centers.
L'archive ouverte pluridisciplinaire HAL, est destinée au dépôt et à la diffusion de documents scientifiques de niveau recherche, publiés ou non, émanant des établissements d'enseignement et de recherche français ou étrangers, des laboratoires publics ou privés. 


\title{
Sensorless Adaptive Output Feedback Control of Wind Energy Systems with PMS Generators
}

\author{
A. El Magri, F. Giri*, G. Besançon ${ }^{\circ}$, A. Elfadili, L. Dugard ${ }^{\circ}$, F.Z. Chaoui \\ Université de Caen Basse-Normandie, GREYC UMR 6072, F-14032 Caen, France \\ ${ }^{\circ}$ Control Syst. Dep., Gipsa-lab UMR 5216, Grenoble INP, 38402 Saint Martin d'Hères, France \\ *Corresponding author: fouad.giri@unicaen.fr
}

\begin{abstract}
This paper addresses the problem of controlling wind energy conversion (WEC) systems involving permanent magnet synchronous generator (PMSG) fed by IGBT-based buck-to-buck rectifier-inverter. The prime control objective is to maximize wind energy extraction which cannot be achieved without letting the wind turbine rotor operate in variable-speed mode. Interestingly, the present study features the achievement of the above energetic goal without resorting to sensors of wind velocity, PMSG speed and load torque. To this end, an adaptive output-feedback control strategy devoid of any mechanical sensor is developed (called sensorless), based on the nonlinear model of the whole controlled system and only using electrical variables measurements. This control strategy involves: (i) a sensorless online reference-speed optimizer designed using the turbine power characteristic to meet the maximum power point tracking (MPPT) requirement; (ii) a nonlinear speed regulator designed by using the backstepping technique; (iii) a sensorless interconnected adaptive state observer providing online estimates of the rotor position as well as speed and load/turbine torque. The proposed output-feedback control strategy is backed by a formal analysis showing that all control objectives are actually achieved. Several simulations show that the control strategy enjoys additional robustness properties.
\end{abstract}

Keywords: wind energy conversion; synchronous generators; speed regulation; MPPT; nonlinear control; output feedback control; adaptive control.

\section{INTRODUCTION}

Due to its renewable nature and reduced environmental impact, wind energy is already playing worldwide an important role in electricity generation and this role is expected to considerably grow up in the near future. Presently, the focus is made on the Wind Energy Conversion (WEC) system of Fig. 1 which includes a Permanent Magnet Synchronous Generator (PMSG) that converts wind turbine power into electric power; the corresponding output voltage amplitude and frequency vary with wind speed. PMS generators offer several benefits in wind power applications due to their high power density, high efficiency (as the copper losses in the rotor disappear), absence of gearbox and reduced active weight. These features make it possible to achieve with PMSG's high varying speed control 
performance and highly reliable operation conditions (reduced need for maintenance). In varyingspeed operation mode, the PMSG is connected to the main power grid through a three-phase power electronic system (see DC/AC part in Fig 1). The three-phase varying frequency and amplitude voltage generated by the PMS machine is rectified using an IGBT-based buck-to-buck rectifier-inverter association (AC/DC/AC PWM converters) connected together with a DC power transfer link (Fig. 1). The AC side of the rectifier is connected to the stator of the PMSG; the inverter (DC/AC) output is directly connected to the grid.

One major requirement in the considered WEC system is controlling the generator rotor speed in order to maximize wind energy extraction. It is well established that the optimal rotor speed is a function of the wind speed value (Fig. 2). It turns out that the achievement of maximum wind energy extraction in presence of varying wind speed conditions necessitates a varying turbine speed operation mode. Specifically, the turbine rotor velocity must be controlled so that its power-speed working point is constantly maintained near the optimal position (Fig. 2). This control objective is commonly referred to 'maximum power point tracking (MPPT)' and its achievement guarantees optimal aerodynamic efficiency. Presently, we seek MPPT achievement with the WEC system of Fig. 1. The global system (including wind turbine, PMSG and AC/DC/AC power converter) has to be controlled in order to achieve a tight reference-speed tracking. Furthermore, the rotor speed reference $\left(\omega_{\text {ref }}\right)$ must be updated online, following the variation of wind velocity $\left(v_{w i n}\right)$, so that the MPPT requirement is achieved. Existing MPPT methods can be separated in two categories. The first one includes methods based on the explicit use of the turbine power characteristics which necessitate online measurements of wind speed and (turbine/PMSG) rotor velocity (e.g. Senjyu et al., 2009). In fact, the required wind speed measurement is a kind of average value of wind speed along the turbine blade which is not easy to measure. This drawback is overcome in (Rocha, 2010) where the proposed MPPT method involves a Kalman predictor estimating the load/turbine torque based on rotor speed measurements. There, the whole control design, including the Kalman predictor, is based on a linear approximation of the WEC systems and no formal analysis is made there for the proposed control strategy (e.g. predictor estimator convergence not proved). The second category of MPPT methods, using the so-called extremumseeking or perturbation-observation technique, do not necessitate turbine characteristics (e.g. González et al., 2010; Hong et al., 2009; Koutroulis et al., 2006; Kesraoui et al., 2011). These methods are most suitable for wind turbines with small inertia.

In this paper, a new control strategy is developed and formally proved to guarantee tight rotor speedreference tracking and rotor speed-reference optimization (for MPPT achievement), without necessitating mechanical sensors for wind and rotor speeds and load torque. The sensorless feature is quite beneficial as it entails cost reduction due to no sensor implementation and maintenance. Interestingly, sensorless (output-feedback) controllers remain beneficial, even when sensors are 
available, for sensor fault detection and isolation and fault tolerant control. Presently, the sensorless aspect is tackled using state observers. Consequently, the proposed output-feedback control architecture involves three main types of components (Fig. 3): speed-reference optimizer, regulators and observers. The online speed-reference optimizer is presently designed, making full use of the nonlinear wind turbine aerofoil characteristic. Rotor speed control is performed using a nonlinear regulator which, in addition, regulates the $d$-component of the stator current to zero, optimizing thus the delivered stator current. Besides, the control strategy regulates the DC link voltage (between $\mathrm{AC} / \mathrm{DC}$ rectifier and inverter) (Fig. 1) to a constant reference value, commonly equal to the nominal PMSG stator voltage. In fact, this regulation loop controls the reactive power control delivered to the grid. All previous regulation loops are developed on the basis of accurate nonlinear models, using the backstepping design technique (Krstic et al., 1995).

The above regulation loops need observers providing them with online estimates of the PMSG rotor flux and load torque and the rotor speed. Only electrical variables are supposed to be accessible to measurements. Observer design for PMSGs has been attempted, following different approaches. In (Zatocil et al., 2008; Ichikawa et al., 1993; Yu-seok et al., 2005) signal injection methods have been proposed making use of the phase inductance variation property by injection of high frequency signal. This approach provides rotor position information at low speeds and during standstill operation. However, it necessitates a certain amount of saliency in the machine. Also, injection of high frequency signal is not desired in high speed operation. Fundamental excitation methods, proposed in e.g. (Silverio et al., 1999), involve the detection of the rotor position from the stator voltages and currents without requiring additional test signals. In (Kittithuch et al., 2007; Chi et al.; 2007), the back EMF (waveform of the voltage induced in stator windings) was used to estimate rotor position by means of state observers or Kalman filters. This approach works well in medium/high speed application while it is not accurate at low operation when the back EMF is low. Presently, a new adaptive observer is developed, on the basis of the nonlinear system model, to get online estimates of the rotor flux, rotor speed and load torque, using only stator voltage/current measurements. The rotor position is derived from the position of the estimated fluxes without requiring initial position detection. The observer is made adaptive to cope with the uncertainty affecting the stator resistance. The observer is designed using the interconnected Kalman like approach initially developed in (Besançon and Hammouri, 1998) for state affine nonlinear systems. The observer development is sustained by a formal analysis proving its convergence.

The control strategy thus developed is illustrated by Fig. 3. It is optimal (in the MPPT sense), multiloop (speed, current, voltage regulation loops) and output-feedback (mechanical and electromagnetic variables observers). It is sustained by a theoretical analysis and a simulation study 
showing the achievement of quite satisfactory control performances, despite the varying wind velocity and the corresponding change in load torque.

The paper is organized as follows: the speed reference optimizer is designed in Section 2; the WEC system under study is modeled and given a state space representation in Section 3; the state-feedback controller is designed and analyzed in Section 4; the adaptive state observer is designed and analyzed in Section 5; simulation results are presented in Section 6. For convenience, the main notations used throughout the paper are described in Table 3 placed at the end of the paper.

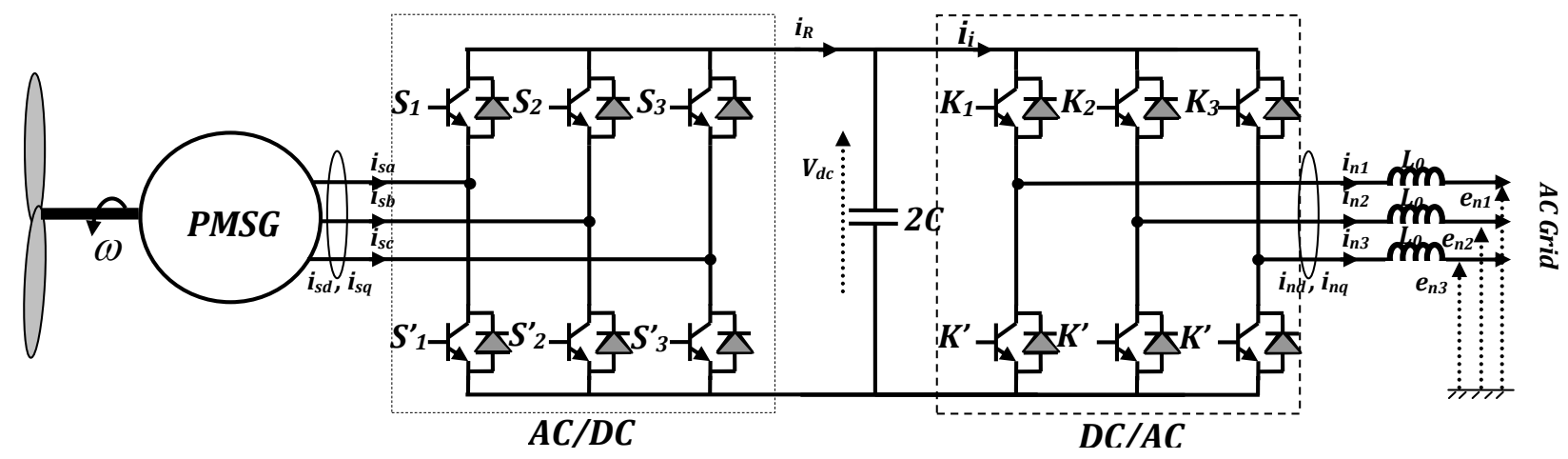

Fig.1. The AC/DC/AC Converter power circuit wind energy conversion system

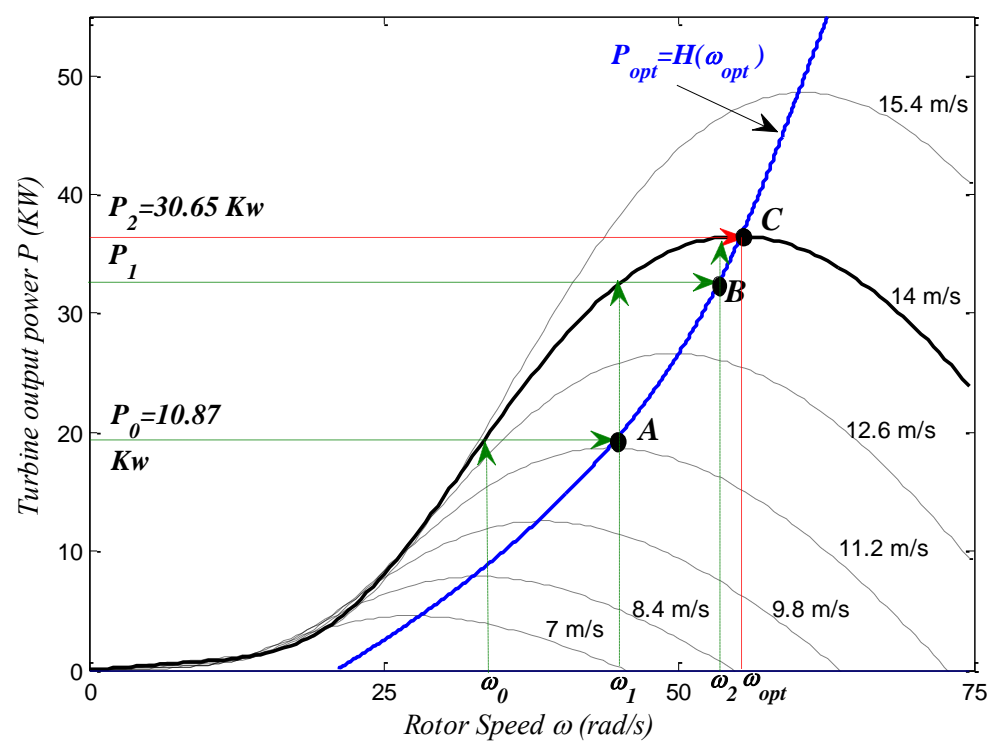

Fig .2 : Turbine Power Characteristics (Pitch angle beta $=0$ deg). 


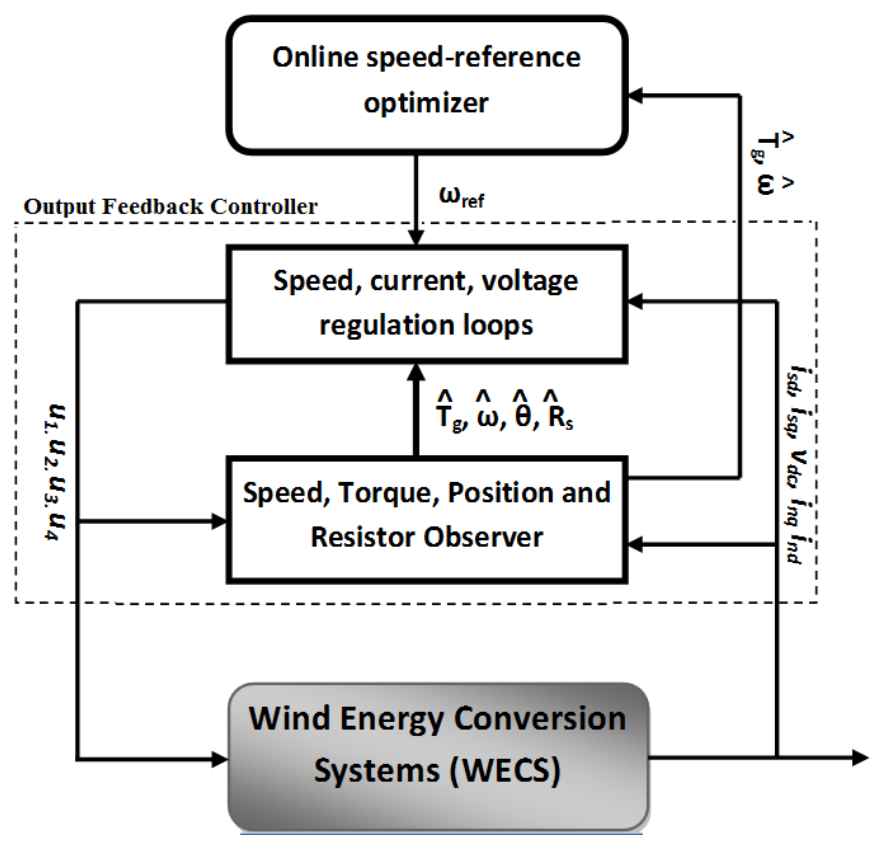

Fig. 3. Control system architecture for WEC systems

\section{WIND SENSORLESS ROTOR SPEED REFERENCE OPTIMIZATION}

In this subsection, we seek the construction of a speed-reference optimizer that meets the MPPT requirement. Specifically, the optimizer is expected to compute online the optimal speed value $\omega_{\text {opt }}$ so that, if the current turbine rotor speed $\omega$ is made equal to $\omega_{\text {opt }}$ then, maximal wind energy is captured, and transmitted to the grid through to the aerogenerator. Presently, the speed-reference optimizer design is based on the turbine power characteristic (Fig. 2) and feature the fact that it does not require wind velocity measurement.

First, let us clarify notations related to turbine power characteristic of Fig. 2. The wind power acting on the swept area of blade A is a function of the air density $\rho\left(\mathrm{Kg} / \mathrm{m}^{3}\right)$ and the wind velocity $v_{\text {win }}(\mathrm{m} / \mathrm{s})$. The transmitted power $P(W)$ is generally deduced from the wind power, using the power coefficient $C_{p}$, as follows:

$$
P=\frac{1}{2} C_{p} \rho \mathrm{A} v_{w i n}^{3}
$$

The power coefficient $C_{p}$ is a nonlinear function of the tip speed-ratio $\lambda=R \omega / v_{\text {win }}$ (with $R$ the turbine radius) which depends on the wind velocity $v_{\text {win }}$ and the rotation speed of the generator rotor $\omega(\mathrm{rad} / \mathrm{s})$. Fig. 2 represents the transmitted power according to the rotor PMSG speed for various values of the wind speed.

The summits of these curves give the maximum 'extractable' power $P_{o p t}$ and so represent the optimal points. Each one of these points is characterized by the optimal speed $\omega_{\text {opt }}$. It is readily seen from Fig. 
2 that for any wind velocity value, say $v_{w i n}^{i}$, there is a unique couple $\left(\omega_{i}, P_{i}\right)$ that involves the largest extractable power. The set of all such optimal couples $\left(\omega_{i}, P_{i}\right)$ is represented by the blue curve in Fig. 2. A number of such couples have been collected from Fig. 2 and interpolated to get a polynomial function $\omega_{o p t}=F\left(P_{o p t}\right)$. Let the obtained polynomial be denoted:

$$
F(P)=h_{n} P^{n}+h_{n-1} P^{n-1}+\ldots+h_{1} P+h_{0}
$$

The values of the degree $n$ and coefficients $h_{i}(i=0 \ldots n)$ corresponding to the characteristic of Fig. 2 are given in Table 2 (see Subsection 5.1). It is precisely this function $F($.$) that defines the speed-$ reference optimizer (Fig. 4). Indeed, suppose that, at some instant, the wind velocity is $v_{\text {win }}^{0}=14 \mathrm{~m} / \mathrm{s}$ and the rotor speed is $\omega_{0}$. One can see on Fig. 2 with the? transmitted wind power $P_{0}$ corresponds to this couple $\left(v_{w i n}^{0}, \omega_{0}\right)$. The point is that $P_{0}$ is easily online computed (as it simply equals the product rotor speed $\times$ torque). Given only the value of $P_{0}$, the speed-reference optimizer gives a new rotor speed reference value $\omega_{1}=F\left(P_{0}\right)$. This corresponds to point A on Fig. 2. Assume that a speed regulator (to be determined) is available, that makes the machine rotor rotate at the new speed reference i.e. $\omega=\omega_{1}$. Then, according to Fig. 2, the wind turbine provides a new extractable power value equal to $P_{1}$. Then, the speed-reference optimizer will suggest (to the speed regulator) a new speed reference $\omega_{2}$ (point $\mathrm{B}$ ). This process will continue until the achievement of the optimal point $\left(P_{\text {opt }}, \omega_{\text {opt }}\right)$ (point C on Fig. 2).

Remark 1. The polynomial interpolation yielding the function $F($.$) has been obtained using the$ Matlab functions MAX, POLYVAL, SPLINE, and POLYFIT.

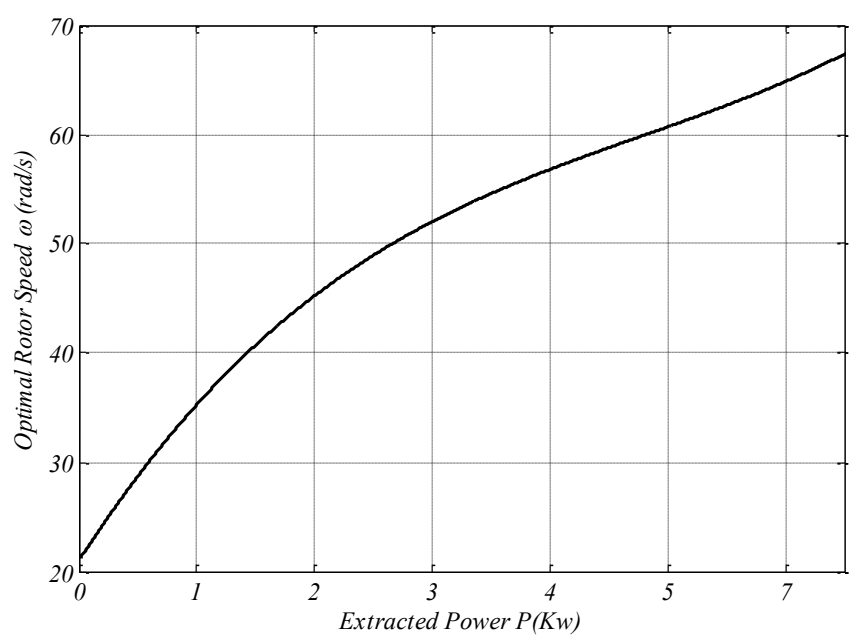

Fig. 4 : Function $\mathrm{F}($.) defining the speed-reference optimizer 


\section{MODELING OF THE ASSOCIATION PMSG -AC/DC/AC CONVERTER}

\subsection{Modeling of the combination 'PMSG-DC/AC converter'}

The controlled system is illustrated by Fig. 1. It includes a combination 'synchronous Generatorrectifier, on one hand, and a tri-phase DC/AC inverter, on the other hand. The rectifier is an AC/DC converter operating, like the DC/AC rectifier, according to the known Pulse Wide Modulation (PWM) principle.

Such a modeling is generally performed in the $\mathrm{d}$-q rotating reference frame (with a rotor position) because the resulting components $i_{s d}$ and $i_{s q}$ turn out to be DC currents. It is shown in many places (e.g Wallmark, 2004) that the synchronous machine model, expressed in the d-q coordinates, can be given the following state space form:

$$
\begin{aligned}
& \frac{d \omega}{d t}=-\frac{F}{J} \omega-\frac{K_{M}}{J} i_{s q}+\frac{1}{J} T_{g} \\
& \frac{d i_{s q}}{d t}=-\frac{R_{s}}{L_{s}} i_{s q}-p i_{s d} \omega-\frac{K_{M}}{L_{s}} \omega-\frac{1}{L_{s}} v_{s q} \\
& \frac{d i_{s d}}{d t}=-\frac{R_{s}}{L_{s}} i_{s d}+p i_{s q} \omega-\frac{1}{L_{s}} v_{s d}
\end{aligned}
$$

where $R_{s}$ and $L_{s}$ are the stator resistor and inductance, $J, F, p$ are the rotor inertia, viscous coefficient and number of poles pairs. $\omega$ is the rotor speed, $T_{g}$ denotes the generator load torque (which equals the turbine shaft torque since the shaft-rotor coupling is presently direct i.e. involves no gearbox), $K_{M}=p \sqrt{3 / 2} \phi_{r}$ is a flux generator constant and $v_{s d}, v_{s q}$ (and $i_{s d}, i_{s q}$ ) denote the averaged stator voltage (and current respectively) in dq-coordinate (Park's transformation of the triphase stator voltages). The inverter is featured by the fact that the stator $\mathrm{d}$ - and q-voltage can be controlled independently. To this end, these voltages are expressed in function of the corresponding control action (see e.g. Michael et al., 1998):

$$
v_{s q}=v_{d c} u_{1} ; \quad v_{s d}=v_{d c} u_{2} ; \quad \bar{i}_{R}=u_{1} i_{s q}+u_{2} i_{s d}
$$

where $u_{1}=\bar{u}_{s q}, \quad u_{2}=\bar{u}_{s d}$ represent the average d-and q-axis (Park's transformation) of the triphase duty ratio system $\left(s_{1}, s_{2}, s_{3}\right)$.

With, $\quad s_{i}=\left\{\begin{array}{lllll}1 & \text { If } & \mathrm{S}_{i} \mathrm{ON} & \text { and } & \mathrm{S}_{i}^{\prime} \mathrm{OFF} \\ 0 & \text { If } & \mathrm{S}_{i} \text { OFF } & \text { and } & \mathrm{S}_{i}^{\prime} \mathrm{ON}\end{array} \quad i=1,2,3\right.$ 
Now, let us introduce the state variables $x_{1}=\bar{\omega}, \quad x_{2}=i_{s q}, x_{3}=i_{s d}$ where $\bar{z}$ denotes the average value on the modulation (MLI) period of the variable $z$. Then, substituting (4) in (3a-b) yields the following state space representation of the association 'Generator-rectifier':

$$
\begin{aligned}
& \dot{x}_{1}=-\frac{F}{J} x_{1}-\frac{K_{M}}{J} x_{2}+\frac{T_{g}}{J} \\
& \dot{x}_{2}=-\frac{R_{s}}{L_{s}} x_{2}-p x_{1} x_{3}+\frac{K_{M}}{L_{s}} x_{1}-\frac{1}{L_{s}} u_{1} v_{d c} \\
& \dot{x}_{3}=-\frac{R_{s}}{L_{s}} x_{3}+p x_{1} x_{2}-\frac{1}{L_{s}} u_{2} v_{d c}
\end{aligned}
$$

where $\dot{z}$ denotes the time-derivative of $z$.

\subsection{DC/AC inverter modeling}

The inverter circuit (DC/AC) is presented in Fig.1 (the right part). The power supply net is connected to a converter which consists of a three phase converter with 6 semiconductors (IGBTs with antiparallel diodes for bidirectional current flow mode) displayed in three legs 1, 2 and 3 . The 6 semiconductors are considered as ideal switches. Only one switch on the same leg can be conducting at the same time.

Applying Kirchhoff's laws, this subsystem is described by the following set of differential equations:

$$
\begin{aligned}
& L_{0} \frac{d}{d t}\left[i_{n 123}\right]=v_{d c}\left[k_{123}\right]-\left[e_{n 123}\right] \\
& 2 C \frac{d v_{d c}}{d t}=i_{r}-i_{i} \\
& i_{i}=\left[k_{123}\right]^{T}\left[i_{n 123}\right]
\end{aligned}
$$

where $\left[i_{n 123}\right]=\left[\begin{array}{lll}i_{n 1} & i_{n 2} & i_{n 3}\end{array}\right]^{T}$ is the input currents in the electric grid, $\left[e_{n 123}\right]=\left[\begin{array}{lll}e_{n 1} & e_{n 2} & e_{n 3}\end{array}\right]^{T}$ is the sinusoidal triphase net voltages (with known constant frequency $\omega_{n}$ ), $v_{d c}$ denotes the voltage in capacitor $2 \mathrm{C}, i_{i}$ designates the input current inverter, and $k_{i}$ is the switch position function taking values in the discrete set $\{0,1\}$. Specifically:

$$
k_{i}=\left\{\begin{array}{c}
1 \text { if } \quad K_{i} \text { is } O N \text { and } K_{i}^{\prime} \text { is } O F F \\
0 \text { if } \quad K_{i} \text { is } O F F \text { and } K_{i}^{\prime} \text { is } O N
\end{array} \quad(i=1,2,3)\right.
$$

To simplify the triphase representation (6a) for the synthesis of control laws, the Park transformation is invoked again. 


$$
\begin{aligned}
& \frac{d i_{n d}}{d t}=-\frac{1}{L_{0}} E_{n d}+\omega_{n} i_{n q}+\frac{1}{L_{0}} u_{n d} v_{d c} \\
& \frac{d i_{n q}}{d t}=-\frac{1}{L_{0}} E_{n q}-\omega_{n} i_{n q}+\frac{1}{L_{0}} u_{n q} v_{d c} \\
& 2 C \frac{d v_{d c}}{d t}=i_{R}-i_{i}
\end{aligned}
$$

where $\left(E_{n d}, E_{n q}\right),\left(i_{n d}, i_{n q}\right)$ and $\left(u_{n d}, u_{n q}\right)$ denote the averaged network voltage and current and input control of the inverter in dq-coordinate (Park's transformation).

The power absorbed by the DC/AC converter is given by the well known expression $P_{\text {Load }}=i_{i} v_{d c}$. On the other hand, the power released by the network is given by $P_{\text {OUT }}=\left[e_{n 123}\right]^{T}\left[i_{n 123}\right]=E_{n d} i_{n d}+E_{n q} i_{n q}$. Using the power conservation principle, one has $P_{\text {Load }}=P_{\text {OUT }}$ or, equivalently $i_{i} v_{d c}=E_{n d} i_{n d}+E_{n q} i_{n q}$. Also, from (8a-b) one immediately gets that:

$$
\begin{aligned}
& 2 v_{d c} \frac{d v_{d c}}{d t}=-\frac{1}{C} E_{n d} i_{n d}-\frac{1}{C}\left(E_{n q} i_{n q}-v_{d c} \bar{i}_{R}\right) \\
& \frac{d i_{n d}}{d t}=-\frac{1}{L_{0}} E_{n d}+\omega_{n} i_{n q}+\frac{1}{L_{0}} u_{n d} v_{d c} \\
& \frac{d i_{n q}}{d t}=-\frac{1}{L_{0}} E_{n q}-\omega_{n} i_{n d}+\frac{1}{L_{0}} u_{n q} v_{d c}
\end{aligned}
$$

Let us introduce the state variables $x_{4}=\bar{v}_{d c}^{2}, \quad x_{5}=\bar{i}_{n d}, \quad x_{6}=\bar{i}_{n q}$. The considered inverter control design will be based upon the following equation:

$$
\begin{aligned}
& \dot{x}_{4}=-\frac{1}{C} E_{n d} x_{5}-\frac{1}{C}\left(E_{n q} x_{6}-v_{d c} \bar{i}_{R}\right) \\
& \dot{x}_{5}=-\frac{1}{L_{0}} E_{n d}+\omega_{n} x_{6}+\frac{1}{L_{0}} u_{3} v_{d c} \\
& \dot{x}_{6}=-\frac{1}{L_{0}} E_{n q}-\omega_{n} x_{5}+\frac{1}{L_{0}} u_{4} v_{d c}
\end{aligned}
$$

where $u_{3}=\bar{u}_{n d}, \quad u_{4}=\bar{u}_{n q}$ represent the average d-and q-axis components of the triphase duty ratio system $\left(k_{1}, k_{2}, k_{3}\right)$.

The state space equations obtained up to now are put together to get a state-space model of the whole system including the AC/DC/AC converters combined with the synchronous generator. For convenience, the whole model is rewritten here for future reference: 


$$
\begin{aligned}
& \dot{x}_{1}=-\frac{F}{J} x_{1}-\frac{K_{M}}{J} x_{2}+\frac{T_{g}}{J} \\
& \dot{x}_{2}=-\frac{R_{s}}{L_{s}} x_{2}-p x_{1} x_{3}+\frac{K_{M}}{L_{s}} x_{1}-\frac{1}{L_{s}} u_{1} v_{d c} \\
& \dot{x}_{3}=-\frac{R_{s}}{L_{s}} x_{3}+p x_{1} x_{2}-\frac{1}{L_{s}} u_{2} v_{d c} \\
& \dot{x}_{4}=-\frac{1}{C} E_{n d} x_{5}-\frac{1}{C}\left(E_{n q} x_{6}-v_{d c} \bar{i}_{R}\right) \\
& \dot{x}_{5}=-\frac{1}{L_{0}} E_{n d}+\omega_{n} x_{6}+\frac{1}{L_{0}} u_{3} v_{d c} \\
& \dot{x}_{6}=-\frac{1}{L_{0}} E_{n q}-\omega_{n} x_{5}+\frac{1}{L_{0}} u_{4} v_{d c}
\end{aligned}
$$

\section{STATE FEEDBACK NONLINEAR CONTROLLER DESIGN}

\subsection{State feedback control objectives}

There are three operational control objectives:

C01. Speed regulation: the machine speed $\omega$ must track, as closely as possible, a given reference signal $\omega_{\text {ref }}$. This reference has been obtained from the MPPT strategy used in order to achieve optimal speed ratio working conditions of the wind turbine to capture the maximum energy from the wind (e.g. Senjyu .T et al., 2009).

CO2. The inverter output currents $\left(i_{n 1}, i_{n 2}, i_{n 3}\right)$ must be sinusoidal with the same frequency as the supplied power grid, the reactive power in the AC grid must be well regulated.

CO3. Controlling the continuous voltage $v_{d c}$ in order to track a given reference signal $v_{d c r e f}$. This reference is generally set to a constant value, equal to the nominal voltage entering the converter and machine.

Since there are four control inputs, there is possibility to account for one more control objective. Commonly, the additional objective is:

CO4. Regulating the current $i_{s d}$ to a reference value $i_{d r e f}$, preferably equal to zero in order to guarantee the absence of d-axis stator current, implying thus no reluctance torque. Doing so, only the q-axis reactance is involved in producing the final voltage, i.e. there is no direct magnetization or demagnetization of d-axis, only the field winding contributes to producing the flux along this direction (see e.g. Muhammad, 2001). 
To achieve these objectives, a nonlinear state feedback controller will be designed in the next subsection. It includes speed and reactive power loops which, together with the speed reference generator designed in Section 2, lead to the temporary state-feedback controller illustrated by Fig. 5 .

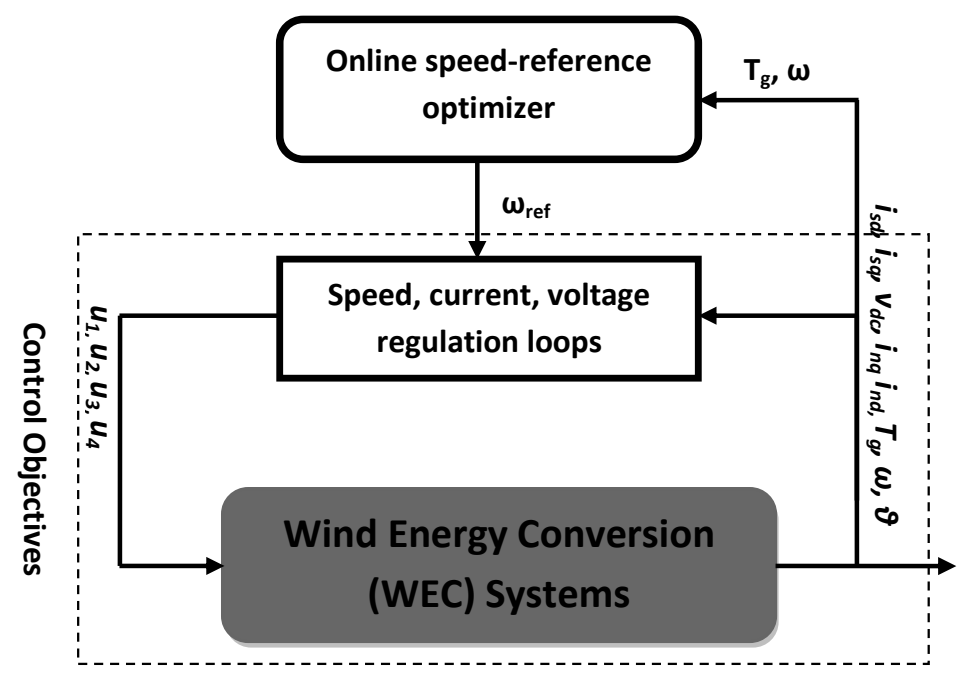

Fig. 5. Temporary state feedback controller for WEC system.

\subsection{Speed regulator design for synchronous generator}

The regulator design is based on equations (11a-b) where the input signal $u_{1}$ stands as the actual input, in order to guarantee speed reference tracking. Following the backstepping technique (Krstic, 1995), let $z_{1}$ denote the speed tracking error:

$$
z_{1}=x_{1}-\omega_{\text {ref }} \stackrel{\text { def }}{=} x_{1}-x_{1}^{*}
$$

In view of (11a), the above error undergoes the following equation:

$$
\dot{z}_{1}=-\frac{F}{J} x_{1}-\frac{K_{M}}{J} x_{2}+\frac{T_{g}}{J}-\dot{x}_{1}^{*}
$$

In (13), the quantity $\alpha=-\left(K_{M} / J\right) x_{2}$ stands up as a (virtual) control input for the $z_{1}$-dynamics. Let $\alpha^{*}$ denote the stabilizing function (yet to be determined) associated to $\alpha$. It is easily seen from (13) that if $\alpha=\alpha^{*}$ with:

$$
\alpha^{*}=\left(-c_{1} z_{1}+\frac{F}{J} x_{1}-\frac{T_{g}}{J}+\dot{x}_{1}^{*}\right) \quad\left(\text { with } c_{1}>0\right. \text { a design parameter) }
$$

Indeed, if $\alpha=\alpha^{*}$ one will have $\dot{z}_{1}=-c_{1} z_{1}$ which clearly is asymptotically stable with respect to the Lyapunov function:

$$
V_{1}=0.5 z_{1}^{2}
$$

Indeed, one then has: 


$$
\dot{V}_{1}=z_{1} \dot{z}_{1}=-c_{1} z_{1}^{2}<0
$$

As $\alpha=-\left(K_{M} / J\right) x_{2}$ is just a virtual control input, one cannot set $\alpha=\alpha^{*}$. Nevertheless, the above expression of $\alpha^{*}$ is retained as a first stabilization function and a new error is introduced:

$$
z_{2}=\alpha-\alpha^{*}
$$

Using (14)-(17), it follows from (13) that the $z_{1}$-dynamics undergoes the following equation:

$$
\dot{z}_{1}=-c_{1} z_{1}+z_{2}
$$

The next step consists in determining the control input $u_{1}$ so that the $\left(z_{1}, z_{2}\right)$ error system is asymptotically stable. First, let us obtain the trajectory of the error $z_{2}$. Deriving $z_{2}$ with respect to time and using (17) gives:

$$
\dot{z}_{2}=-\left(K_{M} / J\right) \dot{x}_{2}-\dot{\alpha}^{*}
$$

Using (14) and (11a-b) in (19), one gets:

$$
\dot{z}_{2}=\chi(x, t)-c_{1}^{2} z_{1}+c_{1} z_{2}+\frac{K_{M}}{J L_{s}} u_{1} v_{d c}
$$

where

$$
\chi(x, t)=\frac{K_{M}}{J}\left(\frac{R_{s}}{L_{s}} \cdot x_{2}+p x_{1} x_{3}-\frac{K_{M}}{L_{s}} x_{1}\right)+\left(\frac{F^{2}}{J^{2}} x_{1}+\frac{F K_{M}}{J^{2}} \cdot x_{2}\right)-\frac{F T_{g}}{J^{2}}+\frac{\dot{T}_{g}}{J}-\ddot{x}_{1}^{*}
$$

The error equations (18) and (20) are given the more compact form:

$$
\begin{aligned}
& \dot{z}_{1}=-c_{1} z_{1}+z_{2} \\
& \dot{z}_{2}=\chi(x, t)-c_{1}^{2} z_{1}+c_{1} z_{2}+\frac{K_{M}}{J L_{s}} u_{1} v_{d c}
\end{aligned}
$$

To determine a stabilizing control law for (22b), let us consider the quadratic Lyapunov function candidate:

$$
V_{2}=V_{1}+0.5 z_{2}^{2}=0.5 z_{1}^{2}+0.5 z_{2}^{2}
$$

Using (18), the time derivative of $V_{2}$ can be rewritten as:

$$
\dot{V}_{2}=-c_{1} z_{1}^{2}+z_{1} z_{2}+z_{2} \dot{z}_{2}
$$

This shows that, for the $\left(z_{1}, z_{2}\right)$-system to be globally asymptotically stable, it is sufficient to choose the control $u_{1}$ so that: 


$$
\dot{V}_{2}=-c_{1} z_{1}^{2}-c_{2} z_{2}^{2}
$$

where $c_{2}>0$ is a new design parameter. In view of (24a), equation (24b) is ensured if:

$$
\dot{z}_{2}=-c_{2} z_{2}-z_{1}
$$

Comparing (25) and (22b) yields the following backstepping control law:

$$
u_{1}=-\frac{J L_{s}}{3 K_{M}}\left(\left(c_{1}+c_{2}\right) z_{2}-\left(c_{1}^{2}+1\right) z_{1}+\chi(x, t)\right) / v_{d c}
$$

\section{3 d-axis current regulation}

The d-axis current $x_{3}$ undergoes equation (11c) in which the following quantity is introduced:

$$
v=p x_{2} x_{1}-u_{2} v_{d c} / L_{s}
$$

As the reference signal $i_{\text {dref }}$ is null, it follows that the tracking error $z_{3}=x_{3}-i_{\text {dref }}$ undergoes the equation:

$$
\dot{z}_{3}=-\left(R_{s} / L_{s}\right) z_{3}+v
$$

To get a stabilizing control signal for this first-order system, consider the following quadratic Lyapunov function:

$$
V_{3}=0.5 z_{3}^{2}
$$

It is easily checked that, if the virtual control is let to be:

$$
v=-\left(-R_{s} / L_{s}+c_{3}\right) z_{3}
$$

where $c_{3}>0$ (a new design parameter), then:

$$
\dot{V}_{3}=-c_{3} z_{3}^{2}
$$

which is negative definite. Furthermore, substituting (29b) in (28), one gets the closed-loop equation:

$$
\dot{z}_{3}=-c_{3} z_{3}
$$

Now, it is readily observed that the actual control input is obtained substituting (29b) into (27) and solving the resulting equation for $u_{2}$. Doing so, one gets:

$$
u_{2}=\left(c_{3} z_{3}-\frac{R_{s}}{L_{s}} z_{3}+p x_{2} x_{1}\right) \frac{L_{s}}{v_{d c}}
$$


The control closed loops induced by the speed and d-axis current control laws thus defined by (26) and (32) are analyzed in the following proposition.

Proposition 1. Consider the control system consisting of the subsystem (11a-c) and the control laws (26) and (32). The resulting closed-loop system undergoes, in the $\left(z_{1}, z_{2}, z_{3}\right)$-coordinates, the following equation:

$$
\left(\begin{array}{l}
\dot{z}_{1} \\
\dot{z}_{2} \\
\dot{z}_{3}
\end{array}\right)=B_{1}\left(\begin{array}{l}
z_{1} \\
z_{2} \\
z_{3}
\end{array}\right) \quad \text { with } B_{1}=\left(\begin{array}{ccc}
-c_{1} & 1 & 0 \\
-1 & -c_{2} & 0 \\
0 & 0 & -c_{3}
\end{array}\right)
$$

This equation defines a stable system and the error vector $\left(z_{1}, z_{2}, z_{3}\right)$ converges exponentially fast to zero, whatever the initial conditions

Proof. Equation (33) is directly obtained from equations (22a), (25) and (31).

It is clear that the matrix $B_{1}$ is Hurwitz, implying that the closed loop system (33) is globally exponentially stable. This completes the proof of Proposition 1.

\subsection{Reactive power and DC voltage controller}

In controlling a PFC (Power Factor Correction?), the main objective is to obtain a sinusoidal output current and the injection or extraction of a desired reactive power in the electric network. The continuous voltage $v_{d c}$ must track a given reference signal $v_{d c r e f}$. These objectives lead to two control loops. The first loop ensures the regulation of the DC voltage $x_{4}$ and the second ensures the injection of the desired reactive power.

\subsubsection{DC voltage loop}

Based on equations (11d-e), a first equation involving the control input $u_{3}$ will now be designed, using the backstepping technique (Krstic .M et al., 2002), so that the squared DC-link voltage $x_{4}=v_{d c}^{2}$ tracks well any reference signal $x_{4}^{*} \stackrel{d e f}{=} v_{d c r e f}^{2}>0$. As the subsystem (11d-e) is of relative degree 2 , the design towards that equation is performed in two steps.

Step 1. Let $z_{4}$ denote the speed tracking error:

$$
z_{4}=x_{4}-x_{4}^{*}
$$

In view of (11d), the above error undergoes the following equation: 


$$
\begin{aligned}
& \dot{z}_{4}=-\frac{1}{C} E_{n d} x_{5}+\beta\left(x_{i=1 \ldots 6}, z_{i=1 \ldots 3}\right)-\dot{x}_{4}^{*} \\
& \beta\left(x_{i=1 \ldots 6}, z_{i=1 \ldots 3}\right)=- \frac{1}{C}\left(E_{n q} x_{6}+\frac{J L_{s}}{3 K_{M}}\left(\left(c_{1}+c_{2}\right) z_{2}-c_{1}^{2} z_{1}+\chi(x, t)\right) x_{2}\right. \\
&\left.-L_{s}\left(c_{3} z_{3}-R_{s} z_{3} / L_{s}+p x_{2} x_{1}\right) x_{3}\right)
\end{aligned}
$$

In (35), the quantity $\alpha_{1}=-E_{n d} x_{5} / C$ stands up as a (virtual) control input for the $z_{4}$-dynamics because the actual control input $u_{3}$ acts on $z_{4}$ indirectly through $\alpha_{1}$. Following the backstepping design technique, the Lyapunov function candidate is considered as: $V_{4}=0.5 z_{4}^{2}$. Deriving $V_{4}$ along the trajectory of (35) yields:

$$
\dot{V}_{4}=z_{4} \dot{z}_{4}=-z_{4}\left(\frac{1}{C} E_{n d} x_{5}-\beta(x, z)+\dot{x}_{4}^{*}\right)
$$

This suggests for the (virtual control) $\alpha_{1}$ the following control law:

$$
\alpha_{1}^{*}=-c_{4} z_{4}-\beta(x, z)+\dot{x}_{4}^{*}
$$

with $c_{4}>0$ a design parameter. Indeed, substituting $\alpha_{1}^{*}$ to $\alpha_{1}=-E_{n d} x_{5} / C$ gives $\dot{V}_{4}=-c_{4} z_{4}^{2}$ which clearly is negative definite in $z_{4}$. As $\alpha_{1}$ is just a virtual control input, one can not set $\alpha_{1}=\alpha_{1}^{*}$. Nevertheless, the above expression of $\alpha_{1}^{*}$ is retained and a new error is introduced:

$$
z_{5}=\alpha_{1}-\alpha_{1}^{*}
$$

Using (37), it follows from (35) that the $z_{4}$-dynamics undergoes the following equation:

$$
\dot{z}_{4}=-c_{4} z_{4}+z_{5}
$$

Step 2. Now, the aim is to make the couple of errors $\left(z_{4}, z_{5}\right)$ vanish asymptotically. The trajectory of the error $z_{5}$ is obtained by time-derivation of (38) i.e.:

$$
\dot{z}_{5}=-\frac{E_{n d}}{C} \dot{x}_{5}+c_{4} \dot{z}_{4}+\dot{\beta}(x, z)-\ddot{x}_{4}^{*}
$$

Using (39) and (11d-e) in (40) yields:

$$
\dot{z}_{5}=\beta_{1}\left(x_{i=1 \ldots 6}, z_{i=1 \ldots .}\right)-\frac{E_{n d}}{C L_{0}} u_{3} v_{d c}
$$

with 


$$
\beta_{1}\left(x_{i=1 \ldots 6}, z_{i=1 \ldots 5}\right)=c_{4} \dot{z}_{4}+\dot{\beta}(x, z)-\ddot{x}_{4}^{*}+\frac{E_{n d}^{2}}{C L_{0}}-\frac{E_{n d}}{C} \omega_{n} x_{6}
$$

To determine a stabilizing control law for (11d-e), let us consider the quadratic Lyapunov function candidate:

$$
V_{5}=0.5 z_{4}^{2}+0.5 z_{5}^{2}
$$

Using (39)-(41), one gets from (42a) that:

$$
\begin{aligned}
& \dot{V}_{5}=z_{4} \dot{z}_{4}+z_{5} \dot{z}_{5} \\
& =-c_{4} z_{4}^{2}+z_{5}\left(z_{4}+\beta_{1}\left(x_{i=1 \ldots 6}, z_{i=1 \ldots .}\right)-\frac{E_{n d}}{C L_{0}} u_{3} v_{d c}\right)
\end{aligned}
$$

This suggests for the control variable $u_{3}$ the following choice:

$$
u_{3}=\left(c_{5} z_{5}+z_{4}+\beta_{1}\left(x_{i=1 \ldots 6}, z_{i=1 \ldots 5}\right)\right) \frac{C L_{0}}{E_{n d} v_{d c}}
$$

where $c_{5}>0$ is a new design parameter. Indeed, substituting (43) in (42b) yields:

$$
\dot{V}_{5}=-c_{4} z_{4}^{2}-c_{5} z_{5}^{2}<0
$$

Now, substituting (43) in (41) one obtains the DC voltage closed-loop control system:

$$
\begin{aligned}
& \dot{z}_{4}=-c_{4} z_{4}+z_{5} \\
& \dot{z}_{5}=-c_{5} z_{5}-z_{4}
\end{aligned}
$$

\section{Reactive Power loop}

Here, the focus is made on the control objective $\mathrm{CO} 3$ that involves the reactive power $Q_{n}$ which is required to track its reference $Q_{n}^{*}$. The electrical reactive power injected in the grid is given by $Q_{n}=E_{n d} x_{6}-E_{n q} x_{5}$. To harmonize notation throughout this section, the corresponding tracking error is denoted $z_{6}=Q_{n}-Q_{n}^{*}$. It follows from (11e-f) that $z_{6}$ undergoes the differential equation:

$$
\dot{z}_{6}=\beta_{2}\left(x_{5}, x_{6}\right)+\frac{v_{d c}}{L_{0}}\left(E_{n d} u_{4}-E_{n q} u_{3}\right)
$$

with

$$
\beta_{2}\left(x_{5}, x_{6}\right)=-\omega_{n}\left(E_{n d} x_{5}+E_{n q} x_{6}\right)-\dot{Q}_{n}^{*}
$$


As the equation (46) is a first order one, it can be (globally asymptotically) stabilized using a simple proportional control law:

$$
v_{d c}\left(E_{n d} u_{4}-E_{n q} u_{3}\right) / L_{0}=-c_{6} z_{6}-\beta_{2}\left(x_{5}, x_{6}\right) \text { with } c_{6}>0
$$

Then the control law $u_{4}$ is given as:

$$
u_{4}=\left(-L_{0}\left(c_{6} z_{6}+\beta_{2}\left(x_{5}, x_{6}\right)\right) / v_{d c}+E_{n q} u_{3}\right) / E_{n d}
$$

It can be easily checked that the dynamic of $z_{6}$ undergoes the following equation:

$$
\dot{z}_{6}=-c_{6} z_{6}
$$

The control closed loops induced by the DC voltage and reactive power control laws thus, defined by (43) and (48) are analyzed in the following proposition.

Proposition 2. Consider the control system consisting of the subsystem (11d-f) and the control laws (43) and (48). The resulting closed-loop system undergoes, in the $\left(z_{4}, z_{5}, z_{6}\right)$-coordinates, the following equation:

$$
\dot{Z}_{2}=B_{2} Z_{2} \quad \text { with } B_{2}=\left(\begin{array}{ccc}
-c_{4} & 1 & 0 \\
-1 & -c_{5} & 0 \\
0 & 0 & -c_{6}
\end{array}\right)
$$

This equation defines a stable system and the error vector $\left(z_{4}, z_{5}, z_{6}\right)$ converges exponentially fast to zero, whatever the initial conditions.

Proof : Equation (50) is directly obtained from equations (45a-b) and (49).

It is clear that the matrix $B_{2}$ is Hurwitz, implying that the closed loop system (50) is globally exponentially stable. This completes the proof of Proposition 2.

Remarks 2. a) The generator speed and the d-component of its stator current both converge to their respective references because the errors $\left(z_{1}, z_{3}\right)$ converge to zero, as a result of Proposition 1.

b) Proposition 2 also demonstrates that tracking objectives are achieved for the DC-link squared voltage $x_{4}=\bar{v}_{d c}^{2}$ and the reactive power $Q_{n}=E_{n d} x_{6}-E_{n q} x_{5}$.

\section{OUTPUT FEEDBACK NONLINEAR CONTROLLER DESIGN}

The controller developed in section 4 has been formally shown to achieve all control objectives listed in subsection 4.1. The point is that this controller was designed using the $\mathrm{d}$-q model which necessitates online measurements of several state variables including the rotor position. As there are no cheap and reliable sensors of these variables, the above controller will remain useless. So, an observer is 
developed providing accurate estimates of the non-measurement variables. The aim of the present section is to design an observer and use it to build up an output feedback controller that does not need measuring the not sensed variables. (à verifier!)

\subsection{Modeling of the PMS Generator in the $\alpha \beta$-frame}

Because the rotor position is not supposed to be available, the PMS Generator model is presently considered in the $\alpha \beta$-frame which is more suitable for observer design (whereas the dq-frame is generally used for its simplicity in control design). According to (Muhammad .H 2001), the PMSG model, in the $\alpha \beta$-coordinates, is given by:

$$
\begin{aligned}
& \dot{i}_{s \alpha}=-a_{1} R_{s} i_{s \alpha}+a_{2} \omega \phi_{r \beta}-a_{3} u_{s \alpha} \\
& \dot{i}_{s \beta}=-a_{1} R_{s} i_{s \beta}-a_{2} \omega \phi_{r \alpha}-a_{3} u_{s \beta} \\
& \dot{\phi}_{r \alpha}=-p \omega \phi_{r \beta} \\
& \dot{\phi}_{r \beta}=p \omega \phi_{r \alpha} \\
& \dot{\omega}=-b_{1}\left(\phi_{r \alpha} i_{s \beta}-\phi_{r \beta} i_{s \alpha}\right)-b_{2} \omega+b_{3} T_{g}
\end{aligned}
$$

where:

$i_{s \alpha}, i_{s \beta}$ denote the stator currents

$\phi_{r \alpha}, \phi_{r \beta}$, designate the rotor fluxes

$u_{s \alpha}, u_{s \beta}$, are the stator voltages

$\omega, T_{g}$ are the angular rotor speed and load torque, respectively.

The subscripts $\mathrm{s}$ and $\mathrm{r}$ refer to the stator and rotor, respectively. The parameters $a_{1}, a_{2}, a_{3}, b_{1}, b_{2}$ and $b_{3}$ are defined by:

$$
a_{1}=1 / L_{s}, a_{2}=p / L_{s}, b_{1}=1.5 p / J, b_{2}=F / J, b_{3}=1 / J \text {. }
$$

Our objective is to design an observer that provides estimates of the state variable $\phi_{r \alpha}, \phi_{r \beta}, \omega, R_{s}$ and $T_{g}$ such that the estimation errors converge to zero. The stator voltage and stator current are assumed to be available. Note that, once flux estimates $\left(\hat{\phi}_{r \alpha}, \hat{\phi}_{r \beta}\right)$ become available, the rotor position can be obtained as follows:

$$
\hat{\theta}=\frac{1}{p} \tan ^{-1}\left(\frac{\hat{\phi}_{r \beta}}{\hat{\phi}_{r \alpha}}\right)
$$


Assume that the load torque value and stator resistor are unknown but constant and that their upper bounds are available. Then, they satisfy the equations:

$$
\dot{T}_{g} \approx 0 ; \dot{R}_{s} \approx 0
$$

The extended PMS Generator model, consisting of (51a-e) and (53), can be seen as an interconnection between two subsystems, denoted by $\Sigma_{1}$ and $\Sigma_{2}$ with:

$$
\begin{aligned}
& \Sigma_{1}\left\{\begin{array}{l}
\dot{X}_{1}=A_{1}\left(X_{2}, y\right) X_{1}+G_{1}\left(X_{2}, y, u\right)+\Phi T_{g} \\
y_{1}=C_{1} X_{1}
\end{array}\right. \\
& \Sigma_{2}\left\{\begin{array}{l}
\dot{X}_{2}=A_{2}\left(X_{1}\right) X_{2}+G_{2}(u) \\
y_{2}=C_{2} X_{2}
\end{array}\right.
\end{aligned}
$$

where:

$$
\begin{aligned}
& A_{1}\left(X_{2}, y\right)=\left[\begin{array}{ccc}
0 & a_{2} \phi_{s \beta} & -a_{1} i_{s \alpha} \\
0 & -b_{2} & 0 \\
0 & 0 & 0
\end{array}\right] ; A_{2}\left(X_{1}\right)=\left[\begin{array}{ccc}
-a_{1} R_{s} & -a_{2} \omega & 0 \\
0 & 0 & -p \omega \\
0 & p \omega & 0
\end{array}\right] \\
& G_{1}\left(X_{2}, y, u\right)=\left[\begin{array}{c}
-a_{1} u_{s \alpha} \\
-b_{1}\left(\phi_{r \alpha} i_{s \beta}-\phi_{r \beta} i_{s \alpha}\right) \\
0
\end{array}\right] ; G_{2}(u)=\left[\begin{array}{c}
-a_{1} u_{s \beta} \\
0 \\
0
\end{array}\right] \\
& \Phi=\left[\begin{array}{lll}
0 & b_{3} & 0
\end{array}\right]^{T} ; C_{1}=C_{2}=\left[\begin{array}{lll}
1 & 0 & 0
\end{array}\right] \\
& X_{1}=\left[\begin{array}{lll}
i_{s \alpha} & \omega & R_{s}
\end{array}\right]^{T} ; \quad X_{2}=\left[\begin{array}{lll}
i_{s \beta} & \phi_{r \alpha} & \phi_{r \beta}
\end{array}\right]^{T}
\end{aligned}
$$

Obviously $u=\left[\begin{array}{ll}u_{s \alpha} & u_{s \beta}\end{array}\right]^{T}$ and $y=\left[\begin{array}{ll}y_{1} & y_{2}\end{array}\right]^{T}=\left[\begin{array}{ll}i_{s \alpha} & i_{s \beta}\end{array}\right]^{T}$ are the control input and measure output vectors of the PMS Generator.

\subsection{Adaptive observer design}

The design strategy consists in synthesizing separately an adaptive observer for each one of the subsystems (54) and (55), according to the methodology of (Besancon et al., 1998) for instance. When focusing on one subsystem, the state of the other one is supposed to be available. The global adaptive observer (that applies to the whole sensorless PMS Generator) is simply obtained by combining the separately designed sub-observers. An input persistency property (Besançon et al., 2006) (that is strongly linked to observability properties of the involved subsystems) is required to guarantee that both the sub-observers and the resulting interconnected one work well, which is stated by the following assumption: 
A1. The pair $\left(X_{2}, y\right)$ and the vector $X_{1}$ are bounded persistently exciting inputs for subsystems (54) an (55) respectively, according to the definition of (Besançon et al., 1996).

A2. The PMS Generator stays in a physical operation domain, denoted by go defined as follows:

$\wp=\left\{X \in \mathfrak{R}^{6}\left|\phi_{r \alpha}\right| \leq \Phi^{M A X},\left|\phi_{r \beta}\right| \leq \Phi^{M A X},\left|i_{s \alpha}\right| \leq I^{M A X},\left|i_{s \beta}\right| \leq I^{M A X},|\omega| \leq \omega^{M A X},\left|T_{g}\right| \leq T_{g}{ }^{M A X}\right\}$

where $X=\left[\begin{array}{llllll}\phi_{r \alpha} & \phi_{r \beta} & i_{s \alpha} & i_{s \beta} & \omega & T_{g}\end{array}\right]^{T}$ denotes the whole state vector and $\left(\Phi^{M A X}, I^{M A X}, \omega^{M A X}, T_{g}^{M A X}\right)$ are the maximal values that the real variables (i.e. fluxes, currents, speed and load torque) can physically take.

Remark 3. 1) Roughly, Assumption A1 means that the input excites the system sufficiently so that its observability is guaranteed. In particular, it entails non-vanishing rotor speed.

2) A direct consequence of Assumption $\mathrm{A} 2$ and definitions of $A_{1}, A_{2}, G_{1}$ is that:

i) $A_{1}\left(X_{2}, y\right)$ is globally Lipschitz w.r.t $X_{2}$ uniformly in $y$

ii) $A_{2}\left(X_{1}\right)$ is globally Lipschitz w.r.t $X_{1}$

iii) $G_{1}\left(X_{2}, y, u\right)$ is globally Lipschitz w.r.t $X_{2}$ uniformly in $y, u$.

Based on the above assumptions, the following observer is obtained by interconnecting (adaptive) Kalman-like sub-observers designed as in (e.g. (Zhang .Q et al., 2003) or (Besançon G. et al., 2006)) for subsystems (54) and (55):

$$
\begin{aligned}
& \dot{\hat{X}}_{1}=A_{1}\left(\hat{X}_{2}, y\right) \hat{X}_{1}+G_{1}\left(\hat{X}_{2}, y, u\right)+\Phi \hat{T}_{g} \\
& +\left[\lambda \Lambda S_{2}^{-1} \Lambda^{T}+\lambda S_{1}^{-1}\right] C_{1}^{T}\left(y_{1}-C_{1} \hat{X}_{1}\right) \\
& \dot{\hat{T}}_{g}=\lambda S_{2}^{-1} \Lambda^{T} C_{1}^{T}\left(y_{1}-C_{1} \hat{X}_{1}\right) \\
& \dot{S}_{1}=-\theta_{1} S_{1}-A_{1}^{T}\left(\hat{X}_{2}, y\right) S_{1}-S_{1} A_{1}\left(\hat{X}_{2}, y\right)+C_{1}^{T} C_{1} \\
& \dot{S}_{2}=-\theta_{2} S_{2}+\Lambda C_{1}^{T} C_{1} \Lambda^{T} \\
& \dot{\Lambda}=\left(A_{1}\left(\hat{X}_{1}, \hat{X}_{2}\right)-\lambda S_{1}^{-1} C_{1}^{T} C_{1}\right) \Lambda+\Phi \\
& \dot{\hat{X}}_{2}=A_{2}\left(\hat{X}_{1}\right) \hat{X}_{2}+G_{2}(u)+S_{3}^{-1} C_{2}^{T}\left(y_{2}-C_{2} \hat{X}_{2}\right) \\
& \dot{S}_{3}=-\theta_{3} S_{3}-A_{2}^{T}\left(\hat{X}_{1}\right) S_{3}-S_{3} A_{2}\left(\hat{X}_{1}\right)+C_{2}^{T} C_{2}
\end{aligned}
$$

where:

$. \hat{X}_{1}=\left[\begin{array}{lll}\hat{i}_{s \alpha} & \hat{\omega} & \hat{R}_{s}\end{array}\right]^{T}, \hat{X}_{2}=\left[\begin{array}{lll}\hat{i}_{s \beta} & \hat{\phi}_{r \alpha} & \hat{\phi}_{r \beta}\end{array}\right]^{T}$ are the state estimates. 
. $\theta_{1}, \theta_{2}, \theta_{3}$ and $\lambda$ are positive design parameters for the observer.

Remark 4. It is known that, if $\left(\hat{X}_{2}, y\right)$ and $\hat{X}_{1}$ satisfy the persistent excitation condition (as in assumption A1) and if the estimates in the above observer remain bounded as in Assumption A2 then, the solutions $S_{1}, S_{2}$ and $S_{3}$ of equations (57c-d) and (58b) are symmetric positive definite matrices with strictly positive upper and lower bounds. In addition, with similar arguments as in e.g. (Besançon et al., 2004), it can be checked that this excitation condition can indeed be inherited from assumption A1 if the parameters $\theta_{1}, \theta_{2}$ and $\theta_{3}$ are large enough.

\subsection{Observer convergence}

In this section, we study the convergence of the proposed observer (57a-e)-(58a-b) on the basis of the above remarks. To that end, let us introduce the estimation errors:

$$
e_{1}^{\prime}=X_{1}-\hat{X}_{1} ; e_{2}=T_{g}-\hat{T}_{g} ; e_{3}=X_{2}-\hat{X}_{2}
$$

Then, it follows from (54)-(55) and (57)-(58) that these errors undergo the following equations:

$$
\begin{aligned}
\dot{e}_{1}^{\prime}= & A_{1}\left(X_{2}, y\right) X_{1}-A_{1}\left(\hat{X}_{2}, y\right) \hat{X}_{1}+G_{1}\left(X_{2}, y, u\right)-G_{1}\left(\hat{X}_{2}, y, u\right) \\
& +\Phi e_{2}+\left[\lambda \Lambda S_{2}^{-1} \Lambda^{T}+\lambda S_{1}^{-1}\right] C_{1}^{T} C_{1} e_{1}^{\prime} \\
\dot{e}_{2}= & -\lambda S_{2}^{-1} \Lambda^{T} C_{1}^{T} C_{1} e_{1}^{\prime} \\
\dot{e}_{3}= & A_{2}\left(X_{1}\right) X_{2}-A_{2}\left(\hat{X}_{1}\right) \hat{X}_{2}-S_{3}^{-1} C_{2}^{T} C_{2} e_{3}
\end{aligned}
$$

Introducing the combined error $e_{1}=e_{1}^{\prime}-\Lambda e_{2}$, one readily gets: $\dot{e}_{1}=\dot{e}_{1}^{\prime}-\dot{\Lambda} e_{2}-\Lambda \dot{e}_{2}$. Using (60a-c) and (57a-e), one has:

$$
\begin{aligned}
\dot{e}_{1}= & {\left[A_{1}\left(\hat{X}_{2}, y\right)-\lambda S_{1}^{-1} C_{1}^{T} C_{1}\right] e_{1}+\left[A_{1}\left(X_{2}, y\right)-A_{1}\left(\hat{X}_{2}, y\right)\right] X_{1} } \\
& +\left[G_{1}\left(X_{2}, y, u\right)-G_{1}\left(\hat{X}_{2}, y, u\right)\right] \\
\dot{e}_{2}= & -\lambda S_{2}^{-1} \Lambda^{T} C_{1}^{T} C_{1}\left(e_{1}+\Lambda e_{2}\right) \\
\dot{e}_{3}= & {\left[A_{2}\left(\hat{X}_{1}\right)-S_{3}^{-1} C_{2}^{T} C_{2}\right\rfloor e_{3}+\left\lfloor A_{2}\left(X_{1}\right)-A_{2}\left(\hat{X}_{1}\right)\right\rfloor X_{2} }
\end{aligned}
$$

From this error system, one can state the following:

Proposition 3: Consider the PMS Generator represented by its combined model (54)-(55) subject to Assumption A1-A2. Consider the interconnected observer described by (57)-(58) restricted to the domain of operation of the system. Let the observer gains, $\theta_{1}, \theta_{2}, \theta_{3}$ and $\lambda$, be chosen large enough so that the following inequalities hold: 


$$
\begin{aligned}
& \delta_{1} \stackrel{\text { def }}{=}\left(\theta_{1}-\mu_{1} v_{1}-\mu_{2} v_{2}\right)>0 \\
& \delta_{2} \stackrel{\text { def }}{=} \theta_{2}-\frac{\mu_{1}}{v_{1}}>0 \\
& \delta_{3}=\theta_{3}-\frac{\mu_{2}}{v_{2}}>0
\end{aligned}
$$

with

$$
\mu_{1}=\frac{\lambda k_{5}}{\sqrt{\lambda_{\text {min }}\left(S_{1}\right)} \sqrt{\lambda_{\text {min }}\left(S_{2}\right)}} ; \mu_{2}=\frac{k_{3} k_{2} k_{21}+k_{1} k_{4} k_{11}+k_{1} k_{13}}{\sqrt{\lambda_{\text {min }}\left(S_{1}\right)} \sqrt{\lambda_{\text {min }}\left(S_{3}\right)}}
$$

where $\lambda_{\min }\left(S_{i}\right) \quad(i=1,2,3)$ is the minimal eigenvalue of $S_{i}, v_{1}, v_{2} \in I R^{* 2}$ are arbitrary, and $k_{i}$ are positive real constants defined in the proof. Then, the observer is exponentially stable, in the sense that the error vector $\left[\begin{array}{lll}e_{1} & e_{2} & e_{3}\end{array}\right]$, defined by (59) and satisfying (61a)-(61c), vanishes exponentially fast, whatever the initial conditions, with a convergence rate fixed by the parameter $\delta=\min \left(\delta_{1}, \delta_{2}, \delta_{3}\right)$

Proof. From assumption A1 and Remark 4, the matrices $S_{1}, S_{2}, S_{3}$, of equations (57)-(58), are used to build up a Lyapunov function candidate in the following way:

$$
W_{0}=W_{1}+W_{2}+W_{3}
$$

where $W_{1}=e_{1}^{T} S_{1} e_{1}, \quad W_{2}=e_{2}^{T} S_{2} e_{2}$ and $W_{3}=e_{3}^{T} S_{3} e_{3}$. Then using (57)-(58) and (61), one gets:

$$
\begin{aligned}
\dot{W}_{0} & =e_{1}^{T}\left\{-\theta_{1} S_{1}-(2 \lambda-1) C_{1}^{T} C_{1}\right\} e_{1}+e_{2}^{T}\left\{-\theta_{2} S_{2}-(2 \lambda-1) \Lambda C_{1}^{T} C_{1} \Lambda\right\} e_{2} \\
& +e_{3}^{T}\left\{-\theta_{3} S_{3}-C_{2}^{T} C_{2}\right\} e_{3}-2 \lambda e_{2}^{T} \Lambda^{T} C_{1}^{T} C_{1} e_{1} \\
& +2 e_{1}^{T} S_{1}\left\{\left(A_{1}\left(X_{2}, y\right)-A_{1}\left(\hat{X}_{2}, y\right)\right) X_{1}+\left(G_{1}\left(X_{2}, y, u\right)-G_{1}\left(\hat{X}_{2}, y, u\right)\right)\right\} \\
& +2 e_{3}^{T} S_{3}\left(A_{2}\left(X_{1}\right)-A_{2}\left(\hat{X}_{1}\right)\right) X_{2}
\end{aligned}
$$

Using again Remark 4, one can have:

$$
\left\|S_{1}\right\| \leq k_{1},\left\|S_{3}\right\| \leq k_{3} \text {, as well as }\left\|\Lambda^{T} C_{1}^{T} C_{1}\right\| \leq k_{5}
$$

for some real constants $k_{i}>0(i=1,3,5)$. Now, referring to Remark 3 and Assumption A2, let us also define notations for bounds on the state vectors and Lipschitz constants as follows:

$$
\begin{aligned}
& \left\|X_{2}\right\| \leq k_{2} ;\left\|X_{1}\right\| \leq k_{4} \\
& \left\|A_{1}\left(X_{2}, y\right)-A_{1}\left(\hat{X}_{2}, y\right)\right\| \leq k_{11}\left\|e_{3}\right\| ;\left\|G_{1}\left(X_{2}, y, u\right)-G_{1}\left(\hat{X}_{2}, y, u\right)\right\| \leq k_{13}\left\|e_{3}\right\|
\end{aligned}
$$




$$
\left\|A_{2}\left(X_{1}\right)-A_{2}\left(\hat{X}_{1}\right)\right\| \leq k_{21}\left\|e_{1}\right\|
$$

Letting in addition $\left\|e_{i}\right\|_{S_{i}}^{2} \stackrel{\text { def }}{=} e_{i}^{T} S_{i} e_{i}(i=1,2,3)$, one has:

$$
\lambda_{\text {min }}\left(S_{i}\right)\left\|e_{i}\right\|^{2} \leq\left\|e_{i}\right\|_{S_{i}}^{2} \leq \lambda_{\max }\left(S_{i}\right)\left\|e_{i}\right\|^{2}
$$

where $\lambda_{\text {min }}\left(S_{i}\right)$ and $\lambda_{\text {max }}\left(S_{i}\right)$ are the minimal and maximal eigenvalues of $S_{i}$.

Coming back to (64) and using (65)-(66), one then gets:

$$
\begin{aligned}
\dot{W}_{0} \leq & -\theta_{1} e_{1}^{T} S_{1} e_{1}-\theta_{2} e_{2}^{T} S_{2} e_{2}-\theta_{3} e_{3}^{T} S_{3} e_{3} \\
& +2 \lambda k_{5}\left\|e_{1}\right\|\left\|e_{2}\right\|+2\left(k_{3} k_{2} k_{21}+k_{1} k_{4} k_{11}+k_{1} k_{13}\right)\left\|e_{1}\right\|\left\|e_{3}\right\|
\end{aligned}
$$

Using (67) and notation (63), inequality (68) implies:

$$
\dot{W}_{0} \leq-\theta_{1} W_{1}-\theta_{2} W_{2}-\theta_{3} W_{3}+2 \mu_{1} \sqrt{W_{1}} \sqrt{W_{2}}+2 \mu_{2} \sqrt{W_{1}} \sqrt{W_{3}}
$$

Remembering that the following inequalities hold for any $v_{1}, v_{2} \in I R^{* 2}$

$$
\begin{aligned}
& \sqrt{W_{1}} \sqrt{W_{2}} \leq \frac{v_{1}}{2} W_{1}+\frac{1}{2 v_{1}} W_{2} \\
& \sqrt{W_{1}} \sqrt{W_{3}} \leq \frac{v_{2}}{2} W_{1}+\frac{1}{2 v_{2}} W_{3}
\end{aligned}
$$

Inequality (69) implies:

$$
\dot{W}_{0} \leq-\left(\theta_{1}-\mu_{1} v_{1}-\mu_{2} v_{2}\right) W_{1}-\left(\theta_{2}-\mu_{1} / v_{1}\right) W_{2}-\left(\theta_{3}-\mu_{2} / v_{2}\right) W_{3}
$$

which gives

$$
\dot{W}_{0} \leq-\delta W_{0}
$$

with $\delta=\min \left(\delta_{1}, \delta_{2}, \delta_{3}\right)$ and

$$
\delta_{1}=\theta_{1}-\mu_{1} v_{1}-\mu_{2} v_{2} ; \delta_{2}=\theta_{2}-\mu_{1} / v_{1} ; \delta_{3}=\theta_{3}-\mu_{2} / v_{2}
$$

In view of (83), $\delta$ can be made positive when the gains $\theta_{i}(i=1,2,3)$ are chosen so that inequalities (62a-c) hold. In that case, one gets from (82) that $W_{0}=\sum_{i=1}^{3}\left\|e_{i}\right\|_{S_{i}}^{2}$ vanishes exponentially fast, which completes the proof of the proposition 3 by standard Lyapunov arguments

\subsection{Output feedback controller}


Following the output-feedback control architecture of Fig. 2, the (not accessible to measurements) mechanical states, involved in the control laws (43) and (48), are now replaced by their online estimates provided by the observer (57)-(58). Doing so, the output feedback controller turns out to be defined by the following control laws:

$$
\begin{aligned}
& u_{1}=-\frac{J L_{s}}{3 K_{M}}\left(\left(c_{1}+c_{2}\right) \varepsilon_{2}-c_{1}^{2} \varepsilon_{1}+\chi\left(\hat{x}_{i=1,2,3}, t\right)\right) / v_{d c} \\
& u_{2}=\left(c_{3} \varepsilon_{3}-\frac{R_{s}}{L_{s}} \varepsilon_{3}+p \hat{x}_{2} \hat{x}_{1}\right) \frac{L_{s}}{v_{d c}} \\
& u_{3}=\left(c_{5} z_{5}+\beta_{1}\left(\hat{x}_{i=1 \ldots 3}, x_{i=4 . .5}, \varepsilon_{i=1 \ldots 3} z_{i=4 . .5}\right)\right) \frac{C L_{0}}{E_{n d} v_{d c}} \\
& u_{4}=\left(-L_{0}\left(c_{6} z_{6}+\beta_{2}\left(x_{5}, x_{6}\right)\right) / v_{d c}+E_{n q} u_{3}\right) / E_{n d}
\end{aligned}
$$

\section{SIMULATION}

\subsection{Simulation and implementation considerations}

a) Simulation of the wind energy conversion (WEC) system

The global control system described by Fig. 6 is simulated using the Matlab/Simulink (V. R2010a), operating under Windows Vista. The controlled part is a WEC system including the synchronous aerogenerator and the associated AC/DC/AC power converters with the numerical values of Table 1. All involved electro-mechanical components are simulated, making use of the SimPower toolbox which offers a quite accurate representation of power elements. In particular, the nonlinearity of static characteristics is accounted for in the toolbox simulated models. Presently, the ODE14x (extrapolation) solver is selected with fixed step time $10 \mu \mathrm{s}$.

\section{b) Implementation of the output-feedback controller}

The output-feedback controller, including the control laws (84a-d) and observers (57-58), is also implemented using Matlab/Simulink resources. The same equation solver as previously is selected. As a matter of fact, the control performances depend, among others, on the numerical values given to the controller/observer parameters i.e. $c_{1}, \ldots, c_{6}, \theta_{1}, \ldots, \theta_{3}$. The point is that there is no systematic way, especially in nonlinear control, to make suitable choices for these values. Therefore, the usual practice consists in proceeding with a try-error approach, leading to the following numerical values:

$$
\begin{aligned}
& c_{1}=9 ; \quad c_{2}=3.10^{4} ; \quad c_{3}=1.10^{3} ; \quad c_{4}=40 ; \quad c_{5}=3.10^{4} ; \quad c_{6}=2.10^{4} \\
& d=2.5 ; \quad \theta_{1}=230 ; \quad \theta_{2}=150 ; \quad \theta_{3}=560 ;
\end{aligned}
$$


When it comes to practical implementation, one should further select a data sampling-time and use a DSP Card. Sampling-time selection is performed, taking into account the controlled system dynamics. Presently, the electrical dynamics are the fastest and so impose the value of the sampling time. From Table 1, the electrical time-constant is $\mathrm{Ls} / \mathrm{Rs}=58.3 \mathrm{~ms}$. Accordingly, a suitable value of the data sampling-time would be $1 \mathrm{~ms}$. Owing DSP card, sophisticated versions exist nowadays (e.g. TEXAS INSTRUMENT card TMS320C6711) making possible to upload the controller Simulink scheme and execute it in real-time in accordance with a so small sampling time. Finally, recall that the sensorless feature of the proposed output-feedback controller entails only the use of electrical (current/voltage) sensors, known to be quite reliable and cheap. Examples of these are the ABB current sensors ES500BR and voltage sensor VS100B, based on the Hall Effect technology

\section{c) Simulation protocols}

Two simulation protocols are described and performed in the sequel:

- The case of the state feedback controller, where all states are assumed available, is considered in Subsection 6.3 . The controller defined by $(26,32,43,48)$ is simulated.

- The case of output-feedback controller defined by (84a-d), where the unavailable states are online estimated, is evaluated in Subsection 6.4.

The controller performances will be evaluated in presence of (time-varying) wind velocity (then rotor speed reference $\omega_{\text {ref }}$ and load torque $T_{g}$ ). According to the control design (Section 4), the remaining closed loop inputs are kept constant, namely $i_{\text {sd ref }}=0 \mathrm{~A}, V_{\text {dcref }}=700 \mathrm{~V}$ and $Q_{\text {ref }}=0 \mathrm{VAR}$.

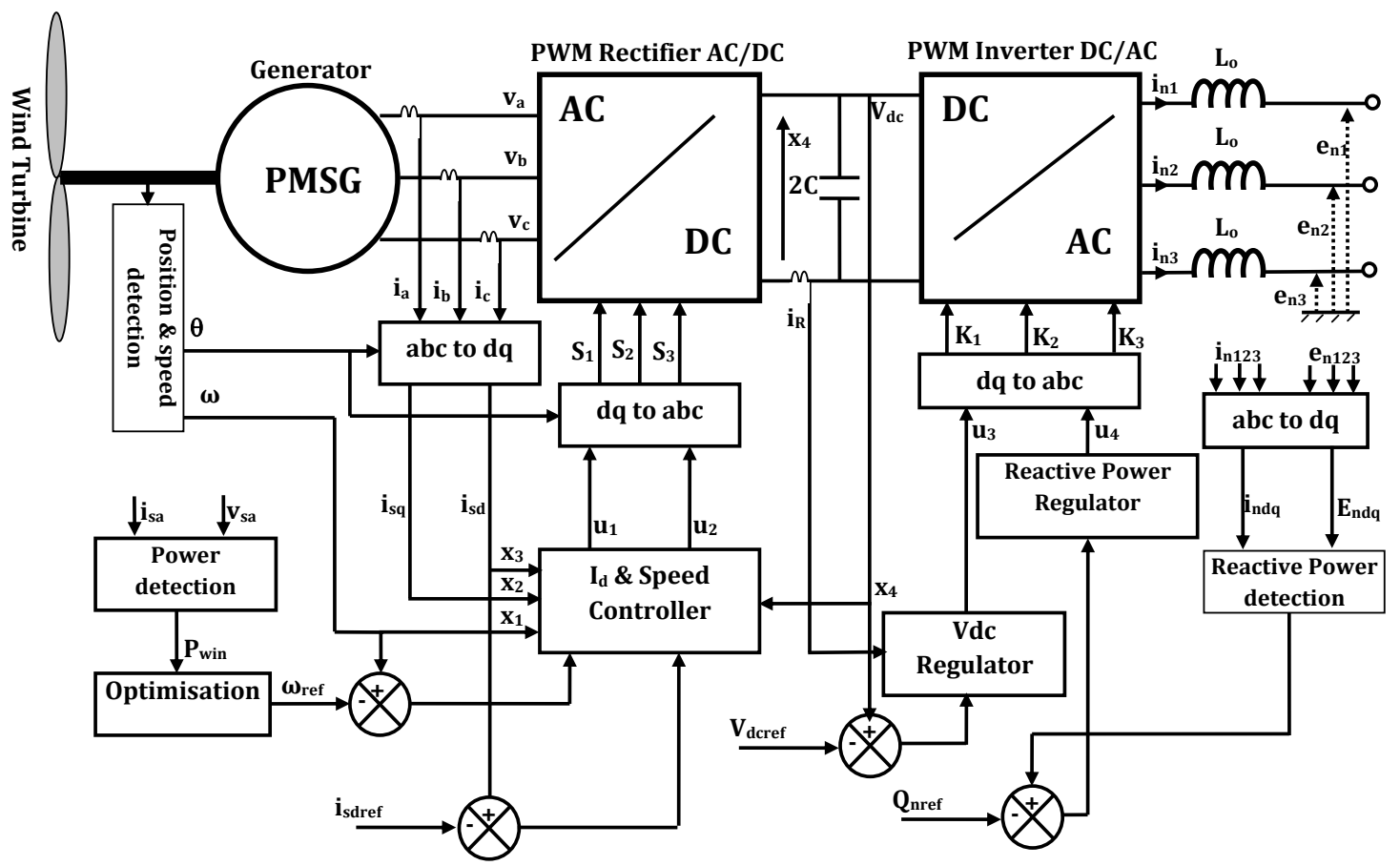

Fig. 6. Control system including AC/DC/AC converters and a synchronous aero-generator. 
TABLE 1. WEC System characteristics

\begin{tabular}{ll}
\hline Supply network voltage : tri-phase & $380 \mathrm{~V}-220 \mathrm{~V} / 50 \mathrm{~Hz}$ \\
\hline AC/DC/AC converters & $\mathrm{L}_{0}=10 \mathrm{mH} ; \mathrm{C}=47 \mathrm{mF} ;$ modulation frequency $10 \mathrm{KHz}$. \\
\hline & nominal power $50 \mathrm{~kW} ; R_{s}=0.3 \Omega ;$ \\
Synchronous generator & $L_{S}=17.5 \mathrm{mH}, \varphi_{\mathrm{r}}=0.876 \mathrm{~Wb} ;$ \\
& $J=8.22 \mathrm{Nm} / \mathrm{rd} / \mathrm{s}^{2}, F=1.417 \mathrm{Nm} / \mathrm{rd} / \mathrm{s} ; p=4$. \\
\hline
\end{tabular}

TABLE 2. Coefficients of polynomial function (2)

$$
h_{0}=1.610^{-7}, h_{1}=0, h_{2}=-2.4910^{-9}, h_{3}=0.0016, h_{4}=21.1984
$$
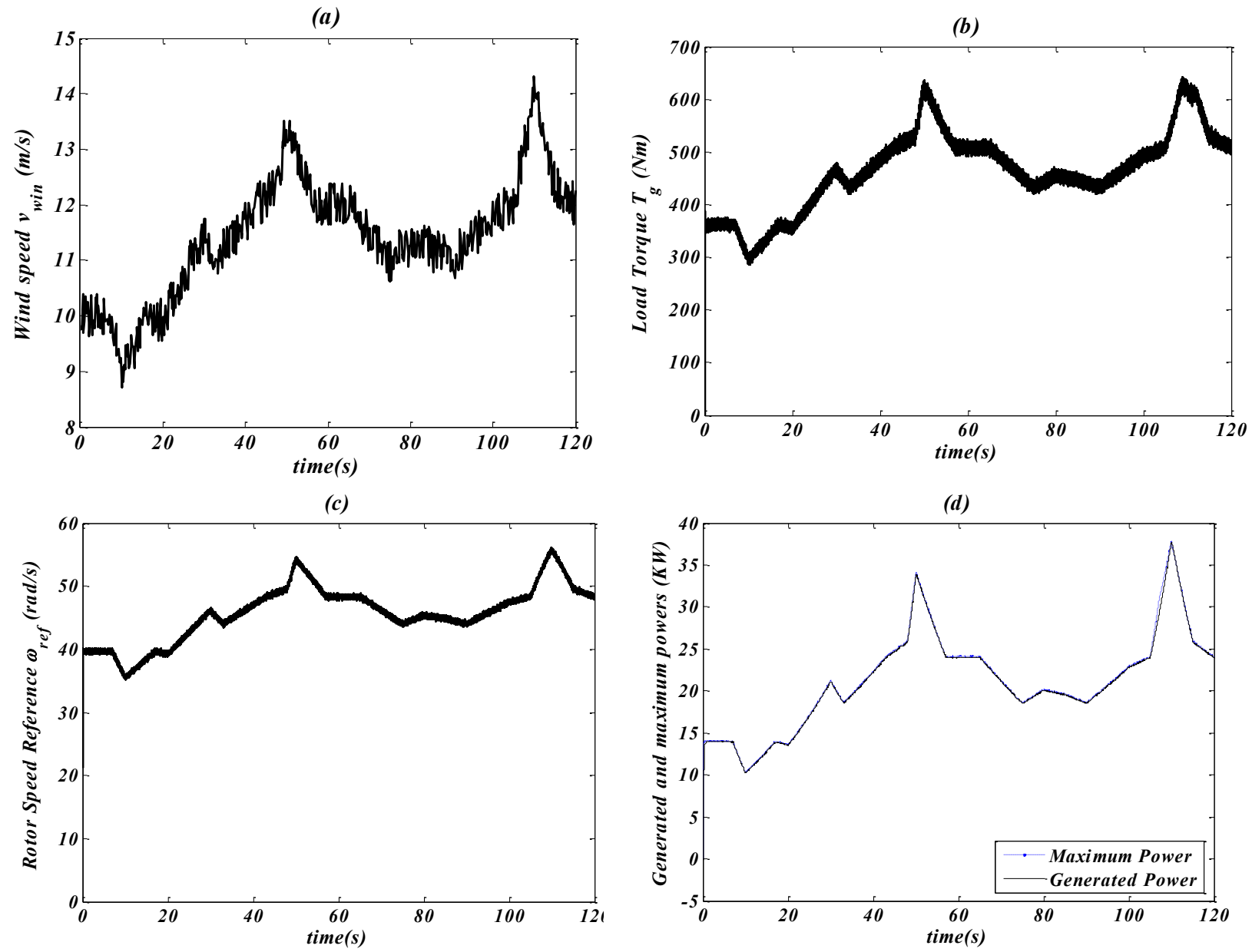

Fig. 7. a) Wind velocity profile $v_{\text {win }}(\mathrm{m} / \mathrm{s}) ;$ b) PMSG load torque $T_{g}(\mathrm{Nm}) ;$ c) Optimized Rotor Speed reference $\left.\omega_{\text {ref }}(\mathrm{rad} / \mathrm{s}) ; d\right)$ Extracted and Maximum Powers $P_{w i n}(K w)$.

\subsection{Construction of the speed reference optimizer}

Fig 7a shows the considered wind speed profile. It is seen that wind speed is noisy and varies between 8.5 and $14.2 \mathrm{~m} / \mathrm{s}$, over the time interval [0,120s]. In response to this wind speed profile, the turbine generates the rotor torque shown in Fig. 7b. Then, the speed optimizer designed in Section 2 generates the rotor speed reference shown in Fig. 7c. Then, Fig. $7 d$ shows the power extracted by the 
synchronous wind generator. Referring to the turbine power characteristics (Fig. 2 and Fig. 4), the extracted active power is optimal for each involved wind speed value.

The polynomial approximation (2) of the characteristic of Fig. 4, is presently given the order 4. The corresponding polynomial coefficients $h_{i}(i=0 \ldots 4)$ have the numerical values of Table 2.

\subsection{Illustration of the state feedback controller performances}

In this subsection, all states are considered as available. The controller performances are illustrated by the curves of Fig. 8. Figs $8 \mathrm{a}$ and $8 \mathrm{~b}$ show that the machine speed, $x_{1}=\omega$ and the d-component of the stator current, $x_{3}=i_{s d}$ perfectly converge to their respective references. The tracking quality is quite satisfactory as the response time (after each change in the wind speed) is small. The curves (c) and (d) respectively show the reactive power injected in the three-phase network $Q_{n}$ (equals zero) and the line current $i_{n 1}$.

It is seen that the current amplitude changes whenever the wind velocity varies (compare with Fig. 8a). The current remains (almost) all time sinusoidal and in phase with the network voltage complying with the PFC requirement. This is particularly demonstrated by Fig $8 \mathrm{j}$ which shows that the input control $u_{3}$ take a constant value, after a small transient time, with the reactive power $Q_{n}$ equals zero. Fig. $8 \mathrm{~g}$ shows the electric power $P_{n}$, produced by the machine and transferred to the grid through the tri-phase inverter. Fig. 8f shows that the DC-link voltage $v_{d c}$ is tightly regulated: it quickly settles down after each change in the wind speed.
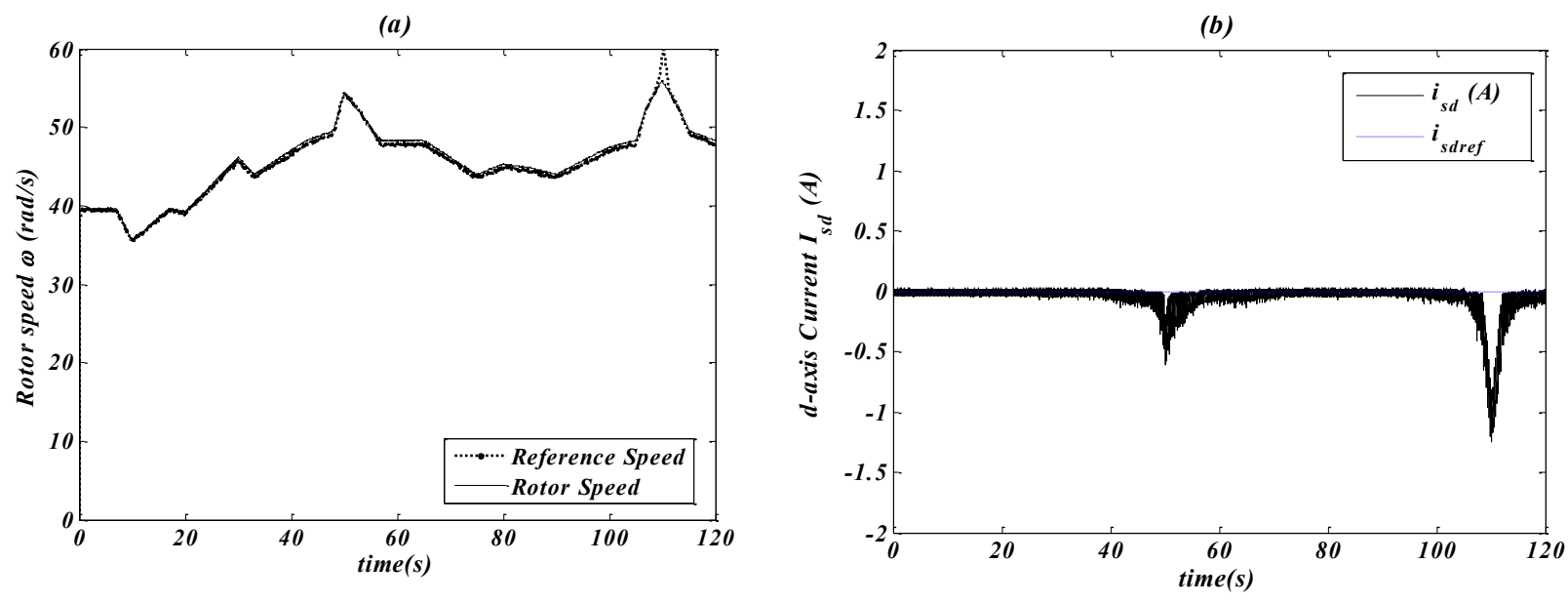
(c)

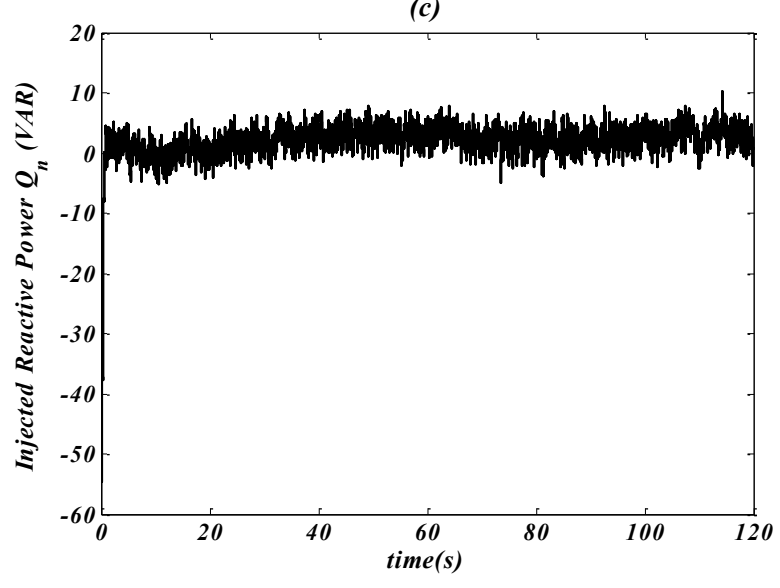

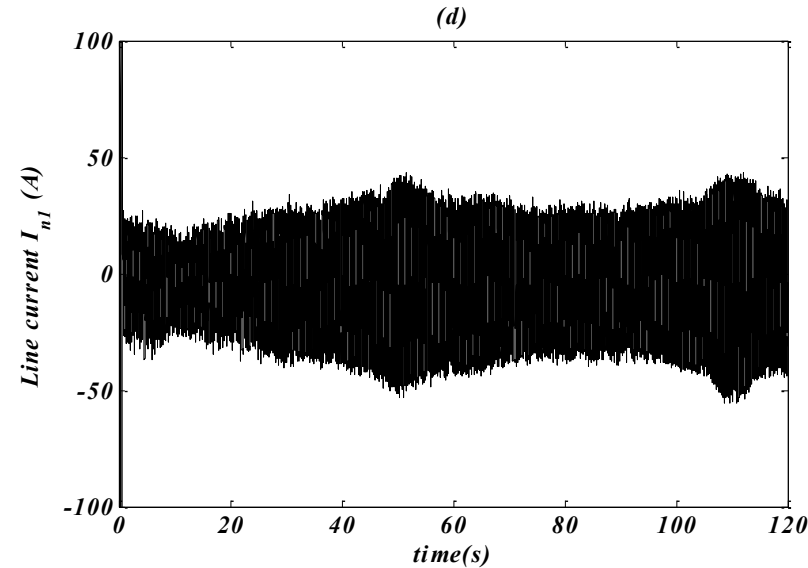

Fig. 8. (part 1). Tracking performances of the controller defined by (26), (32), (43) and (48) in response to the varying wind speed of Fig. $7 a$.

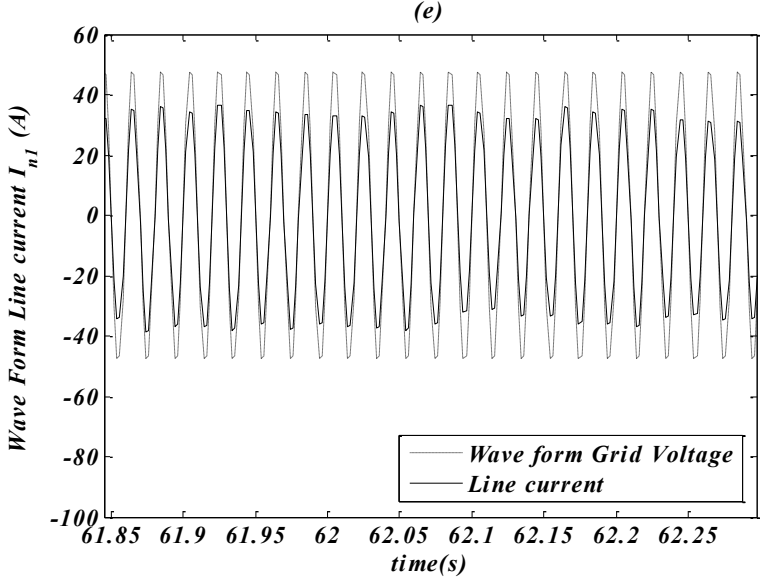

(g)

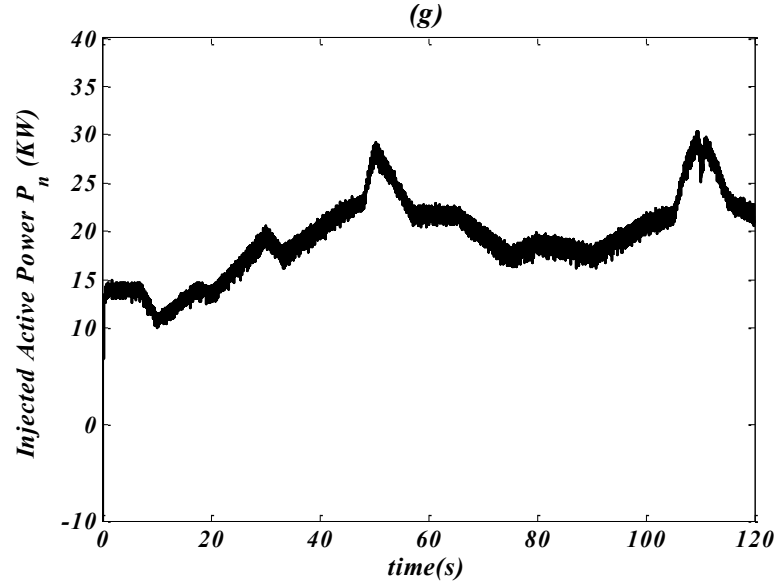

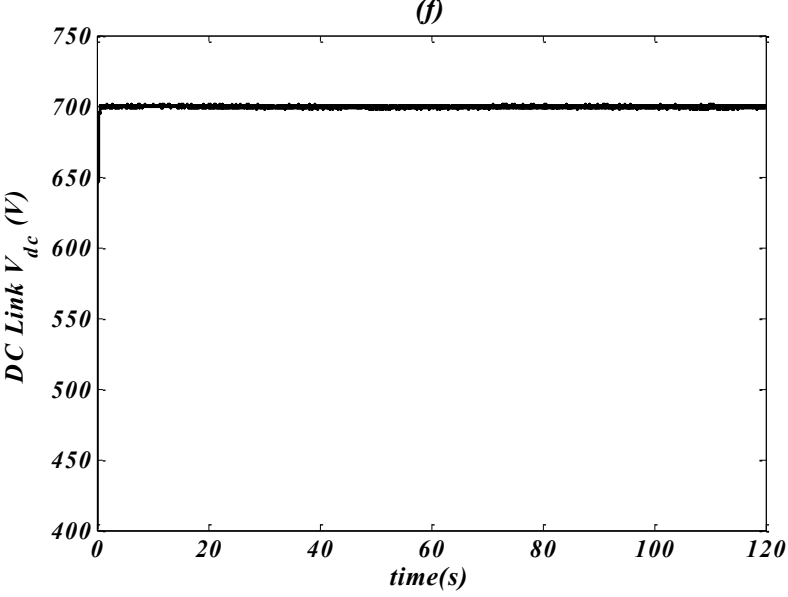

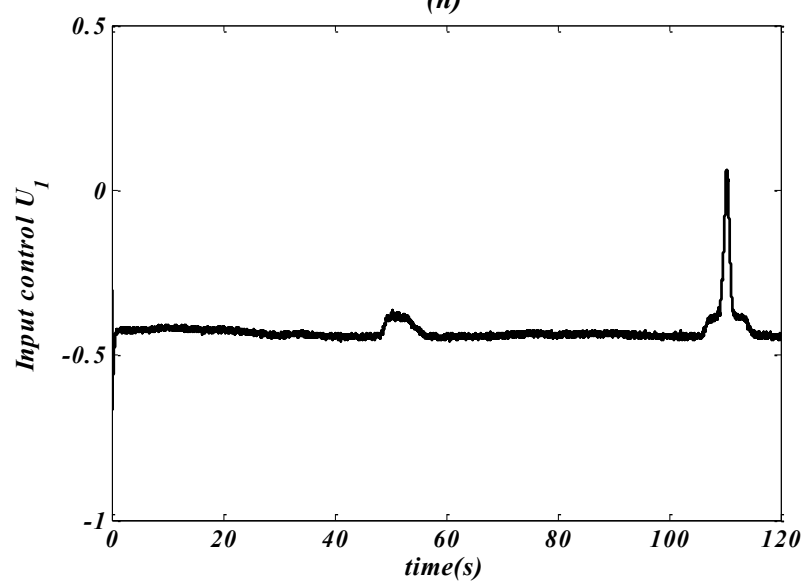



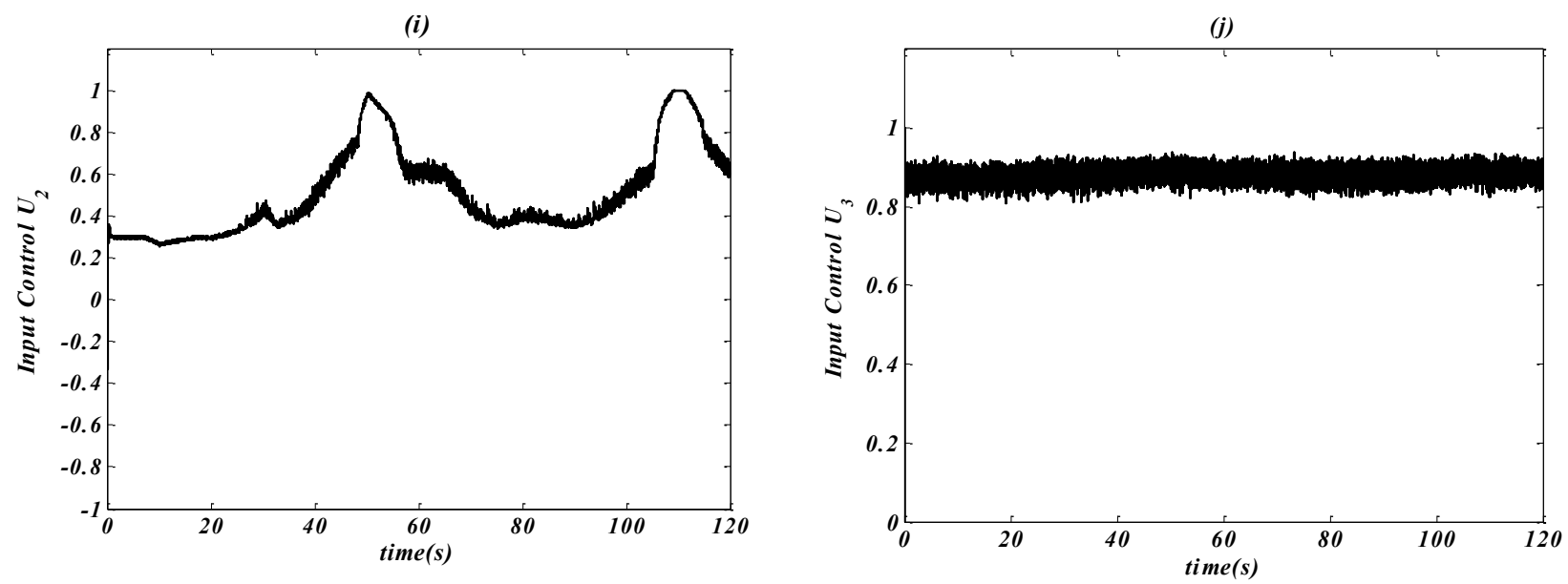

Fig. 8. (part 2). Tracking performances of the controller defined by (26), (32), (43) and (48) in response to the varying wind speed of Fig. $7 a$.

\subsection{Illustration of the output feedback controller performances}

In the following simulations, the mechanical states (rotor speed $\omega$, rotor position $\theta$ and load torque $T_{g}$ ) and the stator resistor $R_{s}$ are no longer available. They are estimated by the observer (57)-(58). The control laws (84) are used to control the WEC system. The output feedback controller performances are illustrated by Fig 9. The curves (a), (b), (c) and (e) show that the tracking quality of the proposed controller/observer is quite satisfactory for all desired references. The disturbing effect, due to the wind velocity change, is also well compensated for by the control laws. 
(a)

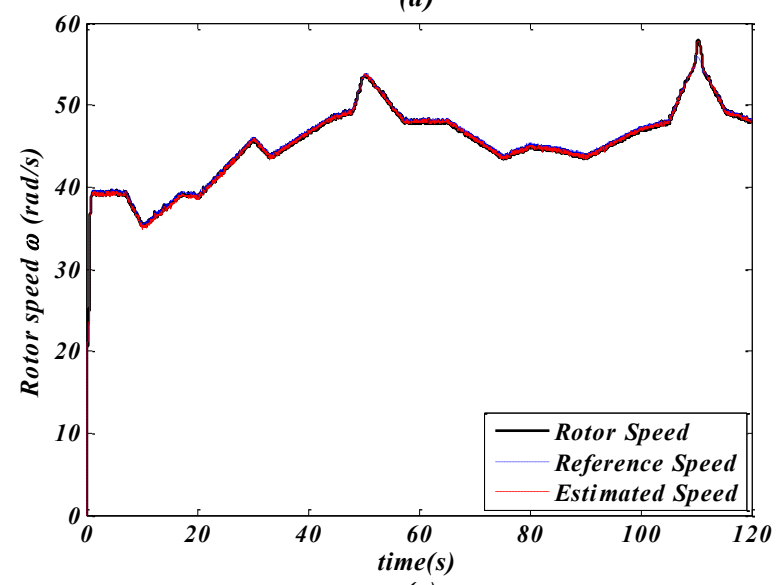

(c)

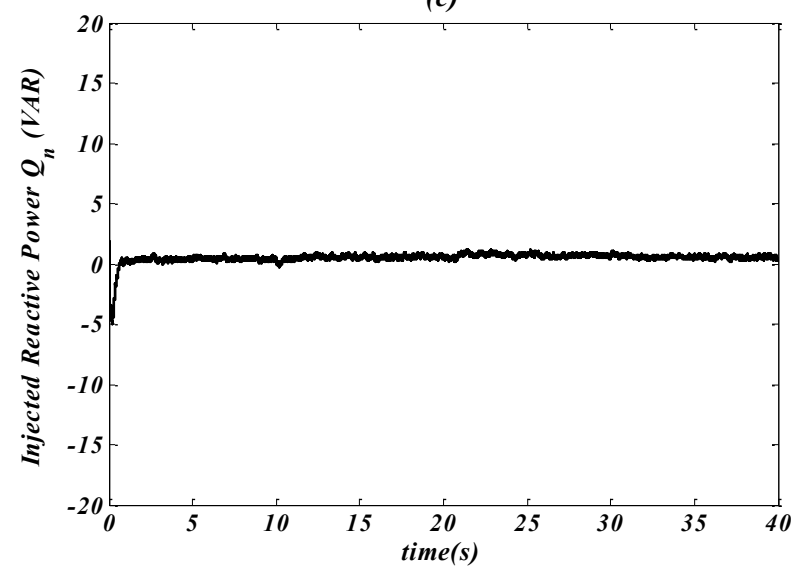

(e)

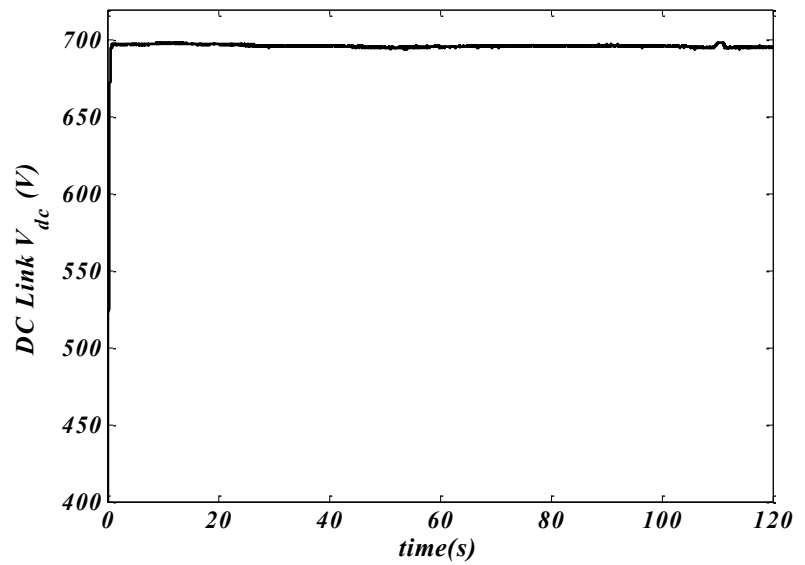

(b)

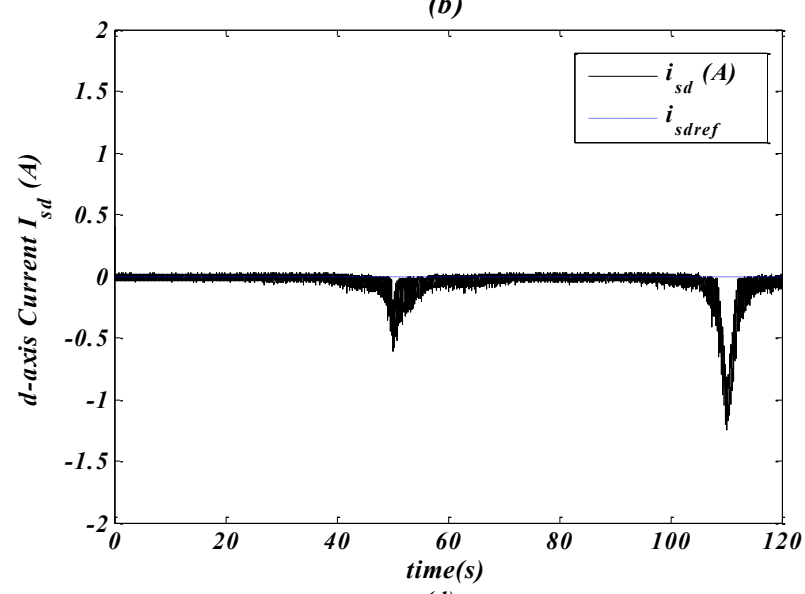

(d)

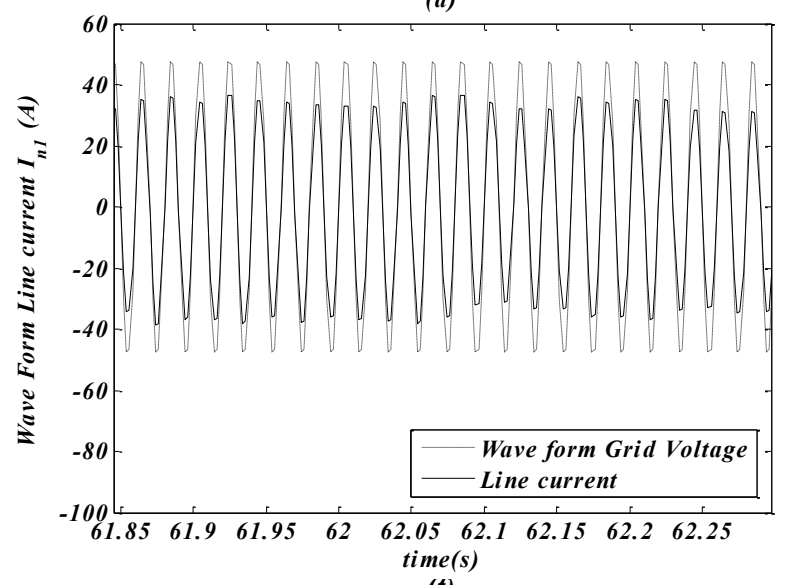

(f)

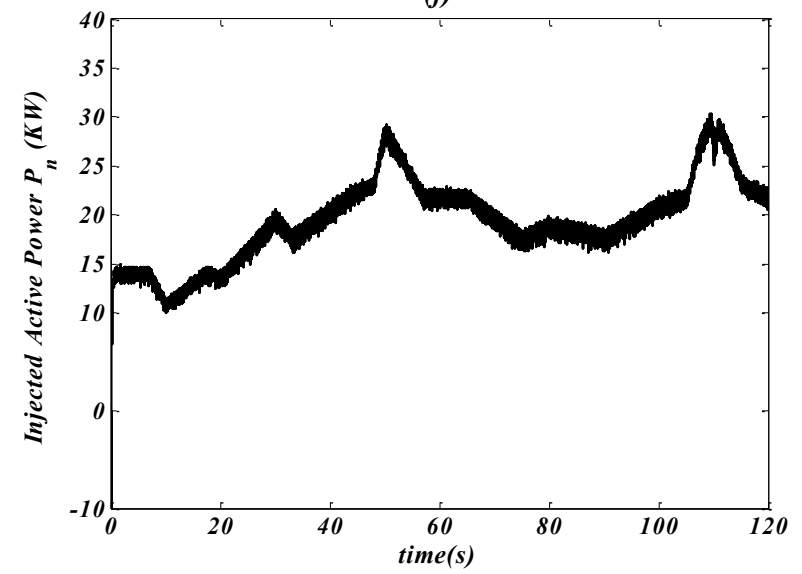

Fig. 9. (part 1). Tracking performances of the controller defined by (84a)-(84d) in response to the varying wind speed of Fig. $7 a$. 

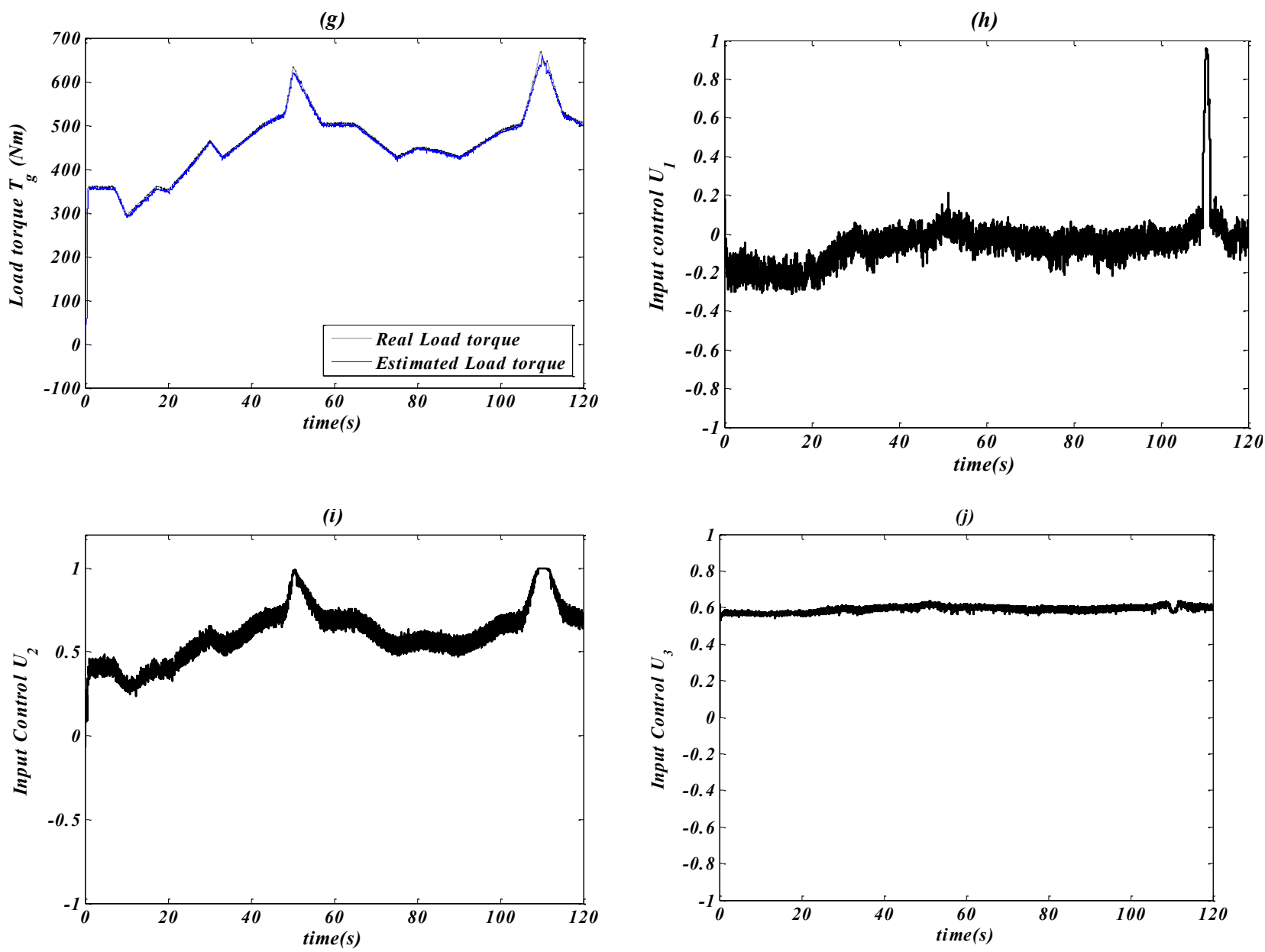

Fig. 9. (part 2). Tracking performances of the controller defined by (84a-d) in response to the varying wind speed of Fig. $7 a$.

\section{CONCLUSION}

We have addressed the problem of sensorless control of the wind energy conversion system. Maximum wind energy extraction is achieved by running the wind turbine generator in variable-speed mode without using the sensor wind velocity. The controlled system is an association including wind turbine, permanent magnet synchronous aero-generator and AC/DC/AC converter connected with a triphase network. The system dynamics have been described by the averaged sixth order nonlinear statespace model (11a-f). First, the multi-loops nonlinear controller, defined by the control laws (26), (32), (43) and (48), has been designed, assuming availability of all states. Then, an interconnected Kalman like observer is proposed to get online estimates of all mechanical state variables in PMSG (rotor position and speed, and load torque). Only the electrical variables are supposed to be accessible to measurements. Based on this observer, the output feedback controller defined by (84a-d) can then be built. The Lyapunov stability and backstepping design technique are used. The controller has been designed to: (i) satisfactory rotor speed reference tracking for extracting maximum power; (ii) tight regulation of the stator d-axis; (iii) power factor correction; (iv) well regulated DC-link voltage $\left(\mathrm{v}_{\mathrm{dc}}\right)$. These results have been confirmed by a simulation study. 
$c_{i}, \theta_{i}:$ design parameters

$e_{n 123}:$ AC line voltages

$E_{n d}, E_{n q}:$ d- and q- axis network voltages

$F$ : combined rotor and load viscous friction

$i_{n 123}:$ line input currents

$i_{s \alpha \beta}:$ Stator currents in $\alpha-\beta$ coordinates

$i_{s d}, i_{s q}: \mathrm{d}$ - and q-axis stator currents

$J$ : combined rotor and load inertia

$L_{0}, C:$ passive components of inverter

$L_{s}, R_{s}$ : inductance and resistance of stator winding (WRSM)

$p:$ number of pole pairs

$Q_{n}:$ Reactive power in the network

$s_{i}, k_{i}: \quad \mathrm{PWM}$ input signals controlling converter IGBT's

$T_{g}$ : machine load torque

$u_{i}$ : average values of $u_{1}, u_{2}, u_{3}, u_{4}$ over cutting periods (duty ratios)

$v_{d c}:$ DC Link voltage

$v_{d c r e f}:$ reference value of DC link voltage $v_{d c}$

$V_{i}, W_{i}$ : Lyapunov functions introduced in the system loops design

$v_{s d}, v_{s q}: \mathrm{d}$ - and q-axis stator voltages

$x_{1}:$ Rotor speed $\left(x_{1}=\omega\right)$

$x_{2}:$ q-axis stator current $\left(x_{2}=i_{s q}\right)$

$x_{3}: \mathrm{d}$-axis stator current $\left(x_{3}=i_{s d}\right)$

$x_{4}: \quad$ squared DC Link voltage $x_{2}=v_{d c}^{2}$

$x_{4}^{*}: \quad$ reference value of $x_{4}$ i.e. $x_{4}^{*}=v_{d c r e f}^{2}$

$x_{5}: \mathrm{d}$-axis line current i.e. $x_{5}=i_{n d}$

$x_{6}:$ Rectifier output voltage $x_{6}=v_{d c}$

$z_{1}$ : rotor speed tracking error $z_{1}=\omega-\omega_{\text {ref }}$

$z_{3}: \mathrm{d}$-axis current tracking error $z_{3}=i_{s d}-i_{\text {sdref }}$

$z_{4}: \quad$ squared DC Link voltage error $z_{4}=x_{4}-x_{4}^{*}$

$z_{6}$ : Reactive power tracking error $z_{6}=E_{n d} x_{6}-E_{n q} x_{5}-Q_{n}^{*}$

$\phi_{r}:$ Rotor flux 


\section{$\phi_{r \alpha \beta}:$ Rotor fluxes in $\alpha-\beta$ coordinates \\ $\omega: \quad$ Rotor angular speed}

\section{REFERENCES}

Besançon G., Bornard G., Hammouri H., (1996). 'Observer synthesis for a class of nonlinear control systems', European Journal of Control, vol. 2, no. 3, pp. 176-192, 1996.

Besançon G., De Leon -Morales J., Huerta-Guevara O., (2006). 'On adaptive Observers for state affine systems', International Journal of Control, Vol 79, No. 6, 2006, pp.581-591.

Besançon G., Hammouri H., (1998). 'On observer design for interconnected systems', Journal of Mathematical Systems, Estimation and Control, vol. 8, no. 3, pp. 1-25, 1998.

Besançon G., Zhang Q., Hammouri H., 'High gain observer based simultaneous state and parameter estimation in nonlinear systems', IFAC Symposium on NOnLinear Control Systems (NOLCOS 04), Germany, 2004.

Boukhezzar B., Siguerdidjane H., (2006), 'Nonlinear Control of Variable-Speed Wind Turbines for Generator Torque Limiting and Power Optimization', J. Sol. Energy Eng., Vol 128, Issue 4, p.516, 2006.

Brahmi J., Krichen L., Ouali A., Traore D., Plestan F., (2009). 'A comparative study between three sensorless control strategies for PMSG in wind energy conversion system', Applied Energy, vol. 86, pp. 1565-1573, 2009.

Chi S., Zhang Z., Xu L., (2007). 'A novel sliding mode observer with adaptive feedback gain for PMSM Sensorless Vector Control', Power Electronics Specialists Conference, IEEE 2007, pp: 2579-258.

Eftichios K., Kostas K., (2006). 'Design of a Maximum Power Tracking System for Wind-Energy-Conversion Applications', IEEE Transactions on Industrial Electronics, Vol. 53, No. 2, April 2006

El Magri A., Giri F., Abouloifa A., El fadili A., (2009). 'Nonlinear Control of Associations Including Wind Turbine, PMSG and AC/DC/AC Converters - Speed regulation and power factor correction', IEEE, European Control Conference 2009, August 23-26, 2009, Budapest, Hungary.

Eriksson S., Solum A., Leijon M., Bernhoff H., (2008). 'A Simulations and experiments on a 12 kW direct driven PM synchronous generator for wind power', Renewable Energy 33 pp. 674-681, 2008.

González L.G., E. Figueres, G. Garcerá, O. Carranza, (2010). 'Maximum-power-point tracking with reduced mechanical stress applied to wind-energy-conversion-systems', Applied Energy 87 pp. 2304-2312, 2010.

Grabic S., Celanovic N., Katic V.A., (2008). 'Permanent Magnet Synchronous Generator Cascade for Wind Turbine Application', Power Electronics, IEEE Transactions, vol 23, May 2008, pp. 1136 - 1142

Hong Y.-Y., Lu S.-D., Chiou C.-S, (2009). 'MPPT for PM wind generator using gradient approximation', Energy Conversion and Management 50 (1), pp. 82-89, 2009

Hong-Woo Kim, Sung-Soo Kim, Hee-Sang Ko, (2010). 'Modeling and control of PMSG-based variable-speed wind turbine', Electric Power Systems Research 80, pp. 46-52, 2010.

Jasiński M., Świerczyński D., Kazmierkowski P., (2007), 'Direct Active and Reactive Power Control of AC/DC/AC Converter with Permanent Magnet Synchronous Generator for Sea Wave Converter', POWERENG`07, Setubal, Portugal, 14-16 April, 2007

Jemaa B., Krichen L., Ouali A., (2009). 'A comparative study between three sensorless control strategies for PMSG in wind energy conversion system', Applied Energy 86, pp: 1565-1573, (2009).

Johnson K. E., Lucy Y.P., Balas M.J., Fingersh L.J., (2006). 'Control of Variable Speed Wind Turbines', IEEE Control System Magazine, Vol. 26, No. 3, pp: 70-81, 2006.

Kesraoui M., Korichi N., Belkadi A., (2011). 'Maximum power point tracker of wind energy conversion system', Renewable Energy, vol. 36 pp. 2655-2662, (2011) 
Khalil, H.K., (2002). 'Nonlinear Systems', Prentice Hall, 3rd edition, ISBN 0-13-067389-7.

Koutroulis E. and K. Kalaitzakis, (2006). "Design of a maximum power tracking system for wind-energy-conversion applications," IEEE Trans. Ind. Electron., vol. 53, no. 2, pp. 486-494, Apr. 2006.

Krstic M., Kanellakopoulos I., Kokotovic P., (1995). 'Nonlinear and adaptive control design', John Wiley \& Sons, Inc, 1995.

Kuroe Y., Okamura K., Nishidai H., Maruhashi T., (1998). 'Optimal speed control of synchronous motors based on feedback linearization'. International Conference on Power Electronics and Variable-Speed Drives, pp 328 - 331.

Michael J, Ryan D., Rik W., (1998). 'Modeling of Sinewave Inverters: A Geometric Approach', Industrial Electronic Conference, IEEE Conference, 1998, vol.1, pp 396 - 401.

Muhammad H., Rashid, (2001). 'Power electronics handbook', Academic press, 2001.

Ohyama K., Arinaga S., Yamashita Y., (2007). 'Modeling and simulation of variable speed wind generator system using boost converter of permanent magnet synchronous generator', European Conference on Power Electronics and Applications, pp. 1-9, 2007.

Rocha R., (2010). 'A sensorless control for a variable speed wind turbine operating at partial load', Renewable Energy (2010) pp. 1-10.

Senjyu T., Ochi Y., Kikunaga Y., Tokudome M., Yona A., Muhando E.B., Urasaki N., Funabashi T., (2009). 'Sensorless maximum power point tracking control for wind generation system with squirrel cage induction generator', Renewable Energy 34 pp. 994-999, 2009.

Senthil Kumar N., Saravanan K., (2004). 'Speed control of PMSM drive using VSI', Industrial Electronic Conference (IECON), Busan, South Korea, Vol. 1, pp 888- 895.

Singh B., Bhuvaneswari G., Garg V., (2006). 'Improved Power Quality AC-DC Converter for Electric Multiple Units in Electric Traction', Power India Conference, pp. 6, 2006.

Sira H., Silva R.. (2006). 'Control design techniques in power electronics devices’. Springer.

Tan K., Islam S., (2008). 'Optimum Control Strategies in Energy Conversion of PMSG Wind Turbine System without Mechanical Sensors', IEEE Transactions on Energy Conversion 19 (2), pp. 392-399, 2008

Traore D., Plestan F., Glumineau A., De Leon J., (2008). 'Sensorless induction motor: high order sliding mode controller and adaptive interconnected observer', IEEE Transactions on Industrial Electronics, vol. 55, (11).pp. 3818-3827. Novembre, 2008.

Zatocil H., (2008). 'Sensorless Control of AC Machines using High-Frequency Excitation' 2008 13th International Power Electronics and Motion Control Conference. 